\title{
LA AGENDA CHINA DE LOS ESTUDIOS INTERNACIONALES: ¿QUIÉNES SON Y DE QUÉ HABLAN?
}

\author{
César Ross ${ }^{1}$ Rodrigo Álvarez ${ }^{2}$ Lenissett Toro-Ibacache $^{3}$ \\ Universidad de Santiago de Chile
}

\begin{abstract}
Resumen:
El artículo explora los efectos del ascenso de China y el declive de los Estados Unidos, en el pensamiento internacionalista y en la política exterior de este país. La hipótesis que guía este artículo sostiene que los internacionalistas se centraron en las tensiones generadas por su política exterior en el mundo, porque el país estaba en un proceso de reposicionamiento global que requería estrategias de reconocimiento, expansión y consolidación, que despertaron la sospecha del mundo. Por estas razones debieron suavizar su discurso, diplomacia y acciones, para avanzar sin confrontar, aunque asumiendo que China es cada vez más una potencia hegemónica. Para abordar esta tarea, se utilizó la metodología de reconstrucción de la agenda del estudio, en un corpus de autores y trabajos abundantemente citados por los especialistas. El resultado de este análisis está estructurado en cuatro partes, una conclusión y un anexo donde se ha incluido el detalle del corpus.
\end{abstract}

Palabras Clave: China, agenda, estudios internacionales, intelectuales-funcionarios, política exterior

Title in English: The China Agenda of International Studies. Who are they and what are they talking about?

\section{Abstract:}

The article explores the effects of the rise of China and the decline of the United States, in internationalist thinking and in the foreign policy of this country. The hypothesis that guides this article argues that the internationalists focused on the tensions generated by their foreign policy in the world, because the country was in a process of global repositioning that required strategies of recognition, expansion and consolidation, which aroused the suspicion of the world. For these reasons they should soften their discourse, diplomacy and actions, to advance without confronting, although assuming that China is increasingly a hegemonic power. To address this task, we used the reconstruction methodology of the study's agenda, in a corpus of authors and works abundantly cited by the specialists. The result of this analysis is structured in four parts, a conclusion and an annex where the detail of the corpus has been included.

Key Words: China, agenda, international studies, intellectual-officials, foreign policy

Copyright (C) UNISCI, 2019.

Las opiniones expresadas en estos artículos son propias de sus autores, y no reflejan necesariamente la opinión de UNISCI. The views expressed in these articles are those of the authors, and do not necessarily reflect the views of UNISCI.

\footnotetext{
${ }^{1}$ Cesar Ross es Profesor Titular de la Universidad de Santiago de Chile (USACH), Investigador del Instituto de Estudios Avanzados (IDEA-USACH), Director Doctorado en Estudios Americanos (IDEA-USACH). Presidente de la Asociación Chilena de Historia de las Relaciones Internacionales. Doctor en Estudios Americanos y Magíster en Historia (USACH). E-mail: < cesar.ross@usach.cl>.

${ }^{2}$ Rodrigo Alvarez es Profesor Adjunto de la USACH. Doctor en Estudios Americanos (USACH), Master of Arts in International Political Economy (Tsukuba University, Japan), Periodista y Licenciado en Ciencias de la Comunicación (UDP. E-mail: < ralvarze@uc.cl>.

${ }^{3}$ Lenissett Toro-Ibacache es coordinadora de doctorado en Estudios Americanos y Magíster en Estudios Internacionales USACH. E-mail: :<lenisset.toro@usach.cl>

DOI: http://dx.doi.org/10.31439/UNISCI-68
} 


\section{Introducción *}

La muy citada obra de Tucídides, Historia de la Guerra del Peloponeso, que para muchos dio lugar al comienzo de los estudios de las Relaciones Internacionales, se concentra en la tensión fundante de la epistemología de este campo de estudio: Comprender y explicar las transformaciones asociadas a las tensiones derivadas del ascenso de unos y de la declinación de otros en la arena internacional.

Llevado al ámbito de los Estados, este movimiento doble genera desafíos relevantes para quienes buscan comprender y explicar el escenario mundial, especialmente cuando esta dinámica de ascenso y caída involucra a los países líderes. ¿Con qué conceptos y teorías se puede entender este tipo de escenarios, bajo contextos históricos diferentes?, ¿con qué categorías analíticas y teórico-metodológicas se puede explicar estas transformaciones? y, tan relevante como lo anterior, ¿con cuánta independencia de los propios principios e intereses se pueden abordar las preguntas anteriores?

Pensar el mundo implica no solo utilizar eficientemente las ideas en circulación y uso, sino que detectar su anomalía y someterlas a ajustes funcionales. Cada época, pero también, cada fuente teórica (escuela, tradición, teoría) aborda esta tarea de maneras propias, así como cada región del mundo, sea por su ubicación dentro del mapa del poder (centro, periferia, norte, sur, semi-periferia, etc.), sea por su singularidad cultural (occidental, oriental, etc.) o por su enfoque teórico-ideológico, más allá y antes de asunciones teóricas a favor o en contra del sistema dominante.

En este marco, el ascenso de la República Popular China ha planteado varios desafíos a los expertos en relaciones internacionales, quienes han buscado evaluar el impacto transformador chino en un sistema internacional dominado por Estados Unidos (EEUU). Para ello se han centrado en el análisis de las distintas variables materiales, así como en las ideas que han dado forma a este proceso y que inevitablemente ponen en tensión el dominio norteamericano en Asia, pero que avanza a nivel global, dejando a ambos Estados atrapadas en lo que algunos autores han denominado el "problema de Tucídides". 4

Este encuentro y/o choque, reúne un número muy alto de las características que podrían denotar una novedad: Se trata de dos países de origen civilizacional diferente, con posiciones contrapuestas (norte-sur) y con enfoques teórico-ideológicos opuestos (liberal-comunista). Sin embargo, parafraseando a Tucídides, no estamos frente a un caso como el Diálogo de los melios: "cuando los flacos contienden sobre aquellas cosas que los más fuertes y poderosos les piden y demandan, conviene ponerse de acuerdo con éstos para conseguir el menor mal y daño posible", 5 sino que a una transición más lenta y compleja, donde la declinación de uno, no le ha forzado a poner su rodilla en tierra; y el ascenso del otro no le ha llevado a la supremacía indiscutible. Aún más, se trata de dos que se oponen y necesitan, en una interdependencia compleja de la cual no pueden escapar fácilmente.

Además, no se trata solo de un nuevo país que se aproxima a la cima del poder mundial, sino que de una cultura y civilización que jamás ha estado en esa posición a escala mundial ¿Cuáles son las fuentes de su pensamiento internacional? ¿con qué teorías están pensando el mundo? ¿cuáles son sus autores de referencia? ¿hasta qué punto la política internacional china

\footnotetext{
${ }^{*}$ Este trabajo es un resultado parcial del proyecto Fondecyt (Fondo Nacional de Desarrollo Científico y

Tecnológico), Concurso Regular No1150375.

${ }^{4}$ Allison, Graham (2017): Destined for War: Can America and China Escape Thucydides's Trap? Boston, Houghton Mifflin Harcourt; Mearsheimer, John (2015): The Rise of China and the Decline of the U.S. Army. San Diego, Didactic Press; Woodhead, Arthur Geoffrey (1970): Thucydides on the Nature of Power. NY, Harvard University Press.

5 Tucídides (1986): La Guerra del Peloponeso. Madrid, España:Ediciones Orbis S.A. p. 321
} 
deriva de las ideas proporcionadas por su intelectualidad-funcionaria (parte del Estado)? Estas preguntas, que abren el programa de investigación, pero que no necesariamente se responden en este trabajo, son críticas para la reflexión futura porque ya no hay dudas de que el proceso de ascenso y consolidación de China a nivel regional y global, en los primeros diez años del siglo veintiuno, así como su creciente influencia en la política internacional, sugiere que estamos no solo frente a un posible nuevo líder mundial, sino que ante una muy bien articulada política, cuyo diseño no es el resultado del azar, sino que de un cuidado análisis. Éste, como han sugerido muchos autores, implementado con efectividad por los gobiernos chinos y sus líderes durante los últimos cuarenta años, ha sido concebido por una intelectualidad profesional que trabaja al servicio del Estado y para el engrandecimiento de éste.

Frente a estas interrogantes, la pregunta central es ¿Quiénes componen este grupo? ¿cuáles son sus ideas y obras? Para responder estas preguntas de análisis, este artículo identificará a los expertos que están escribiendo sobre China y sus ideas en marco del estudio de las relaciones internacionales, entre los años 2000 y 2010, período en el que China emerge al estatus de gran potencia, creando una nueva dinámica en el Este de Asia que amenazó la posición estratégica de EEUU. ${ }^{6}$

Teniendo en cuenta que el propósito central de este trabajo es configurar un especie de mapa, la hipótesis que guía este artículo sostiene que los internacionalistas (chinos y chinólogos ${ }^{7}$ ) se enfocaron, principalmente en las tensiones generadas por su política exterior en el mundo, debido a que el país se encontraba en un proceso de reposicionamiento global que requería de estrategias de reconocimiento, expansión y consolidación, , que despertó la sospecha del mundo, por lo que ellos debieron suavizar su discurso, diplomacia y acciones, a fin de avanzar sin confrontar.

El objetivo central de este artículo es agregar a una reflexión en marcha, un mapa que contiene la estructura del debate de quienes producen ideas, directa (intelectuales-funcionarios) e indirectamente (intelectuales autónomos), para alimentar el proceso de análisis y decisión que impulsa el pensamiento internacionalista y la política exterior de China durante el período 2000 y 2010. Esta última dimensión no se comprueba empíricamente en este texto, sino que se infiere especulativamente, porque deviene de una investigación exploratoria que está abriendo un camino.

La metodología del trabajo se centra en la reconstrucción de la agenda de los estudios sobre China, que hace referencia a un conjunto de temas organizados en torno a su relevancia, tradiciones intelectuales, teorías en circulación, preguntas e hipótesis y dirección de los debates específicos de las comunidades epistémicas hegemónicas. ${ }^{8}$ Este ejercicio, que en cualquier circunstancia es básico y útil para cualquier investigador, resulta especialmente relevante para conocer el mapa de autores e ideas sobre la política china.

Las fuentes en que se basa este estudio dice relación con el corpus comentado más adelante, compuesto por 44 autores y 48 títulos.

La estructura de este artículo se presenta en cuatro partes: La primera, hace referencia a los enfoques en uso; la segunda a la reconstrucción de la agenda de estudios, como metodología

\footnotetext{
${ }^{6}$ Arase, David (2016): China's Rise and Changing Order in East Asia. New York, Palgrave Macmillan.

${ }^{7}$ No ocuparemos el concepto "sinólogo", habitualmente en uso, porque el se refiere a los estudios chinos, en cuanto disciplina académica, focalizada en el estudio de China principalmente a través del pensamiento, el idioma, la literatura, la cultura y la historia de China. Muchos de los autores examinados en este estudio con concuerdan con dicha definición, en tanto se ocupan de algunos aspectos de China y no de todas las dimensiones aceptadas comúnmente para esta categoría.

${ }^{8}$ Ross, César (2016): Patent No. 268.546. Chile.
} 
de trabajo; la tercera, se ocupa de exponer los resultados preliminares; y la cuarta, los efectos del ascenso en la política exterior de china.

\section{Enfoques en uso}

El ascenso chino ha sido descrito y observado por políticos e intelectuales chinos (y no chinos) que han buscado entender y explicar el lugar de China en el nuevo siglo. ${ }^{9}$ Para el desarrollo de esta tarea, la política cerrada del gobierno chino y las diferencias culturales fueron el primer obstáculo para comprender cuál sería su estrategia política, más allá de las declaraciones que el propio gobierno difundía.

En este escenario, los enfoques en uso durante la primera década del siglo veintiuno estuvieron dedicados, principalmente en identificar los centros de investigación chinos (think tanks) y las teorías en debate (de relaciones internacionales), pero menos en identificar a los expertos chinos, y no chinos (chinólogos), que estaban "hablando" sobre la emergencia del país. Esto último, tal vez porque la urgencia estaba en develar la estrategia política china y para ello conocer el grado de compromiso estatal y disciplinario de los centros de investigación gubernamentales y universitarios era fundamental. ${ }^{10}$

En esta búsqueda, los think tanks chinos son una importante fuente de información para los expertos en estudios internacionales por lo que identificarlos y clasificarlos fue una tarea urgente, ya que hasta fines del siglo veinte ${ }^{11}$ estas instituciones no habían sido relevantes por lo que su estudio se hizo urgente. De hecho, la revista The China Quarterly, editada por la Cambridge University Press, presentó un número especial en el 2002 dedicado a estos centros de investigación chinos. ${ }^{12}$

En este número, David Shambaugh, de la George Washington University, buscó establecer el rol de estos centros de investigación en los años ochenta y noventa, con el objetivo de proyectar su influencia en los primeros años del siglo veintiuno y en particular el estudio que estos think tanks estaban realizando frente a la inevitable interacción de Asia con Occidente. Para el académico, la contribución de estos centros ha sido vital para la comprensión que China está haciendo del mundo:

Como resultado, los funcionarios y líderes de China están ahora mejor informados sobre el mundo, lo cual, es de esperar, significa que comprenden mejor las consecuencias de sus acciones antes de tomarlos. ${ }^{13}$

\footnotetext{
${ }^{9}$ Algunos de ellos son: Ryosei, Kokubun y Wang, Jisi (2004): The Rise of China and a Changing East Asian Order. Tokio, Japan: Japan Center Intl Exchange; Ikenberry, John; Feng, Zhu y Wang, Jisi (2015): America, China, and the Struggle for World Order: Ideas, Traditions, Historical Legacies, and Global Visions. New York, Palgrave Macmillan; Arase, D. (2016). op. cit. p.2.

${ }^{10}$ No obstante, se debe poner atención a trabajos publicados de manera muy reciente que muestran los resultados de una búsqueda de autores chinos, que desde el siglo XX, han cuestionado las cuentas oficiales del gobierno chino. Veg, Sebastian (2019): Minjian: The Rise of China's Grassroots Intellectuals. New York, Columbia University Press.

${ }^{11}$ La investigación de los estudios internacionales tomó relevancia a principio de los años ochenta cuando se lanzó la estrategia nacional de reforma y apertura del país.

${ }^{12}$ Algunos de los artículos de ese número fueron: Changing Windows on a Changing China: The Evolving "Think Tank" System and the Case of the Public Security de Murray Scot Tanner; China's International Relations Think Tanks: Evolving Structure and Process de David Shambaugh; Chinese Civilian Foreign Policy Research Institutes: Evolving Roles and Increasing Influence de Bonnie S. Glaser y Phillip C. Saunders; Chinese Military-Related Think Tanks and Research Institutions de Bates Gill y James Mulvenon; China's Economic Think Tanks: Their Changing Role in the 1990s de Barry Naughton.

${ }^{13}$ Shambaugh, David: "China's International Relations Think Tanks: Evolving Structure and Process", The China Quarterly, nº171 (septiembre 2002), p.596.
} 
En esta misma publicación, Bonnie S. Glaser del Center for Strategic and International Studies (CSIS) y Phillip C. Saunders del Institute for National Strategic Studies de la National Defense University, sostienen que los think tanks se desarrollaron en el marco del ascenso chino, la creciente interacción con los otros países, una política exterior más pragmática y un proceso de formulación de políticas más burocrático, todo lo cual aumentó las oportunidades (y la competencia) para la participación de centros de investigación civiles en las políticas internacionales. $^{14}$

Un importante aporte a la comprensión de estos centros fue la que realizaron los académicos de la Tsinghua University, Zhu Xufeng y Lan Xue. Ambos publicaron trabajos, en conjunto y por separado, donde clasificaron los think tank de acuerdo al grado de compromiso e independencia de las políticas del gobierno, así como su influencia en la toma de decisiones, y que clasificaron en dos categorías: los think tanks de instituciones públicas (semioficiales) y los think tanks universitarios (civiles). ${ }^{15}$

Los primeros, estaban dirigidos y financiados por el gobierno, por lo que parte de sus investigaciones están determinadas por los intereses centrales (de alguna agencia en particular). Se les permite tener financiamiento de otras agencias de gobierno, incluso desde el extranjero, lo que derivó en tareas de investigación distintas que los llevó, incluso, a generar informes independientes donde criticaron al gobierno. ${ }^{16}$

Los segundos, son más pequeños y su afiliación gubernamental es menor. Cuentan con apoyo económico nacional e internacional y están conformados por académicos de las distintas universidades, algunos de renombre, que mantienen vínculos con los funcionarios del gobierno, lo que no implica que no tengan libertad para hacer críticas a éste. ${ }^{17}$

Otra forma de conocer la estrategia y el pensamiento chino fue abordando su propuesta y llevándolo al campo de estudio de Relaciones Internacionales. Al igual que en el caso de los think tanks, a fines del siglo veinte comenzó observar la proliferación de académicos y centros de investigación dedicados al estudio de las relaciones internacionales. Estos registraban un fuerte sesgo occidental pues muchos de los investigadores chino se formaron en Estados Unidos, por lo cual la teoría se vio fuertemente influenciada por estas escuelas y por las corrientes realistas, liberales y constructivistas. ${ }^{18}$ No obstante, el presente estudio arroja que algunos conceptos como seguridad, no contempla las mismas preocupaciones que en las políticas norteamericanas.

Un importante aporte a la divulgación de este conocimiento ha sido la revista, International Relations of the Asia-Pacific que ha dedicado distintos números especiales al estudio de las relaciones internacionales no occidentales, donde los aportes chinos al debate tienen un lugar destacado.

\footnotetext{
${ }^{14}$ Glaser, Bonnie y Saunders, Phillip: “Chinese Civilian Foreign Policy Research Institutes: Evolving Roles and Increasing Influence”, The China Quarterly, n¹71 (septiembre 2002), p. 597-616.

${ }^{15}$ Xufeng, Zhu y Xue, Lan: "Think Tanks in Transitional China”, Public Administration and Development, $\mathrm{n}^{\circ} 27$ (noviembre 2007), p.452-464; Xufeng, Zhu: "The Influence of Think Tanks in the Chinese Policy Process: Different Ways and Mechanisms", Asian Survey, vol. 49, n² (marzo-abril 2009), p. 333-357.

${ }^{16}$ Ibíd. Algunos de estos centros son: Chinese Academy of Social Sciences (CASS), el Development Research Center of the State Council (DRC), Shanghai Institute for International Studies (SIIS) y el China Development Institute (CDI).

${ }^{17}$ Ibíd. Algunos de estos centros son: China Center for Economic Research (CCER), National Economic Research Institute (NERI), Dajun Center for Economic Watch \& Studies

${ }^{18}$ En este período se enviaron a traducir al chino las obras de Jans J. Morgenthau, Karl Deutsch, Kenneth Waltz, Stanley Hoffman, Robert O. Keohane, Joseph S. Nye, Immanuel Wallerstein y Alexander Wendt (Qin, 2013).
} 
En un balance del estado de las propuestas teóricas de relaciones internacionales chinas realizado por Qin Yaqing, actual presidente de la China Foreign Affairs University, afirmó que la ocupación mayor de los intelectuales fue desarrollar una teoría propia de validez universal, ya que las propuestas occidentales no explicaban del todo la realidad china y en especial la creciente tensión que se estaba produciendo con la emergencia del país. ${ }^{19}$ De hecho, durante la primera década del siglo veintiuno se registró un aumento en la búsqueda de debates teóricos europeos y propios, pero el norteamericano siguió siendo dominante. Como resultado, se multiplicaron los artículos científicos de relaciones internacional en el país y teorías que explicaran el "ascenso pacífico" de China (temática más recurrente en este período), por lo que el idealismo (y las propuestas derivadas) fueron las más recurrentes.

En todo este proceso, la identificación de chinos influyentes fue posible a partir del estudio de los think tanks y de las revistas científicas. Esta revisión de sus publicaciones nos reveló grupos, filiación, temáticas y dificultades teóricas, pero poco respecto a individualizar ¿quiénes hablan y de qué hablan? Cosa que si se logró utilizando la metodología de la agenda de estudios planteada en este trabajo.

\section{Reconstrucción de la agenda de estudios. Metodolosgía de trabajo}

Para los efectos de reconstruir la agenda de estudio se ha utilizado la metodología que uno de los autores de este trabajó, César Ross, creó para la sistematización de conjunto de temas organizados en torno a su relevancia, tradiciones intelectuales, teorías en circulación, preguntas e hipótesis y dirección de los debates específicos de las comunidades epistémicas hegemónicas. ${ }^{20}$

Para seleccionar adecuadamente la lista de autores y obras es clave identificar eficazmente los temas de la agenda de estudios, lo cual implica hacer consultas a expertos e identificar las obras de mayor referencia sobre la temática que se busca investigar. Se sugiere identificar: La lista de temas de una disciplina, ${ }^{21}$ el significado de cada uno de ellos, una jerarquización de las mismas, ${ }^{22}$ las preguntas, hipótesis y argumentos de los autores.

Hecho este trabajo, se tendrá a disposición la arquitectura completa del debate académico sobre una cuestión dada, lo que facilita tener una noción clara respecto de cuántas y cuáles son las preguntas en circulación, cuántas y cuáles son las hipótesis que responden a esas preguntas, quiénes defienden cada una de las posiciones que agrupan y dividen este conjunto de razonamientos. En definitiva, tener una certeza de lo que Pierre Bourdieu llamó "campo de fuerza" ${ }^{23}$.

En esta elaboración se parte de la base que el debate chinos y chinólogos, como otros en el ámbito académico y político, se desarrolla en un número limitado de centros de pensamiento y por un número reducido de intelectuales de los cuales solo algunos corresponden a intelectuales que tienen la capacidad de influir en la política internacional de su país. Identificarlos supone conocer sus obras clásicas, pero sobre todo implica conocer a quienes han

\footnotetext{
${ }^{19}$ Qin, Yaqing: "Development of International Relations theory in China: progress through debates" International Relations of the Asia-Pacific, vol.11, n², (mayo 2011), p. 231-257.

${ }^{20} \mathrm{Su}$ aplicación se puede encontrar en el artículo: Ross, César y Montaner, Gonzalo: "La agenda de los estudios de seguridad post 9/11: ¿de qué y quiénes hablan?”, Revista de Relaciones Internacionales, Estrategia y Seguridad, vol. 12, no2 (julio-diciembre 2017), p.15-42.

${ }^{21}$ Cada ciencia, disciplina y subdisciplina aborda un conjunto de temas: algunos son de carácter permanente y otros son de tipo temporal. Los primeros responden a la naturaleza de cada ciencia, disciplina y subdisciplina y los segundos corresponden a las tendencias estacionales, a veces muy largas, del debate académico.

${ }^{22}$ La jerarquización le confiere a cada tema un estatus que para las comunidades científicas se constituyen en una señal de relevancia y/o de urgencia.

${ }^{23}$ Bourdieau, Pierre: "Los tres estados del capital cultural”, Sociológica, vol. 2, n5 (1987), p. 11-17.
} 
estado elaborando las ideas específicas que constituyen las claves del ascenso chino de los últimos años. Por decirlo de alguna forma, ¿quiénes son los Nicholas Spykman, Hans Morgenthau, Samuel Huntington, Henry Kissinger y Joseph Nye Jr. de China? Es estricto sensu, no lo sabemos y deberíamos. Esta tarea deberá estar en el centro de las futuras investigaciones referidas a este problema de análisis.

Sin embargo, no siempre es evidente la forma de hacer esta selección, especialmente porque los investigadores tienen la tendencia de utilizar a los mismos autores casi para todos los trabajos, sea por cercanía o por sesgos teóricos y/o ideológicos.

\subsection{Reconstrucción de la agenda: Selección de autores y obras}

Como se indicó al comienzo, este artículo reconstruye la agenda de estudios china en el ámbito de las relaciones internacionales, identificando y sistematizando las publicaciones de la primera década del siglo veintiuno (2000-2010), ${ }^{24}$ período en el ascenso chino capturó la atención de varios especialistas que buscaron dar respuesta de este nuevo fenómeno y sus posibles consecuencias.

Para identificar a los autores e ideas más relevantes de este período se siguieron tres líneas de acción: se comenzó con una consulta a expertos, siguió con la revisión de distintas obras y luego se identificaron los temas más relevantes que, junto al análisis, permitieron construir la agenda de estudios china.

La primera, consistió en contactar a expertos de distintas nacionalidades (diplomáticos y académicos de renombre) a quienes se les hizo la pregunta ¿Quiénes cree usted fueron las autoras y autores (de todo el mundo) que escribieron sobre China más destacados durante el período 2000-2010? Con las respuestas, se elaboró una primera lista de 10 nombres (que estuvo compuesta solo por chinos) que permitió continuar con el proceso siguiente, donde fueron apareciendo los expertos no chinos: A este grupo de expertos lo denominamos "chinólogos".

La segunda, consistió en buscar las publicaciones de los autores de la lista inicial para conocer sus obras, ${ }^{25}$ identificar las más relevantes y sus autores de referencias (con los que debatían o asentían). Esta parte de la investigación hizo crecer la nómina inicial hasta alrededor de 100 expertos, la que luego se depuró (redujo) atendiendo a quiénes concentraban el mayor número de citas. Como resultado se pudo confeccionar un corpus de 44 chinólogos y 48 títulos con mayor número de referencias, ${ }^{26}$ que publicaron entre los años 2000 y $2010 .{ }^{27}$

La tercera, consistió en identificar los temas de interés más recurrentes en las obras seleccionadas, lo que permitió determinar las temáticas más debatidas en el período. Este procedimiento arrojó una lista de temas principales y secundarios, de acuerdo a cómo las y los autores elaboraron sus estudios (Tabla 4). Como para cada procedimiento, el resultado obtenido

\footnotetext{
${ }^{24}$ Este período corresponde a los gobiernos de Jiang Zemin (1993-2005) y de Hu Jintao (2005-2013), y que es el período en donde este ascenso tiene particular dinamismo.

${ }^{25}$ Se denomina obras a todas las publicaciones destinadas a la difusión de ideas, lo que incluyó: Artículos académicos, artículos de opinión, libros, capítulos de libro y ponencias en congresos. Es decir, no solo se incluyeron publicaciones de tipo científica, sino también de divulgación ya que, en una primera etapa, este estudio se centró principalmente en las ideas producidas en el período de estudio que produjeron un debate, más allá de si estas fueron acompañadas de teoría, metodología y base empírica.

${ }^{26}$ Esta investigación reconoce que, como en cualquier investigación social, puede contar con omisiones de autores y obras que tal vez son importantes y que no fueron nombrados por los expertos y tampoco aparecieron en la revisión de las obras revisadas, no obstante, mediante esta metodología se ha comprobado en otras investigaciones (Ross y Montaner, 2017) que se puede alcanzar el dibujo bastante preciso de un mapa de autores y temas relevantes, en un período determinado.

${ }^{27}$ Lo que incluyó 13 obras publicadas entre el 2011 y 2012, pero que correspondía a ideas producidas durante el período de estudio
} 
es un reflejo de las opciones de quienes realizaron los trabajos examinados, en cuando a sus identificaciones de temas principales y temas secundarios, pero subordinados a los primeros.

Como resultado final de estas tres líneas de acción, se logró reconstruir un mapa de autores y un listado de temas desarrolladas durante la primera década del siglo veintiuno en el campo de los estudios sobre china y en el marco del campo de las Relaciones Internacionales. Podría afirmarse, usando la expresión que hemos elegido para este trabajo, que hemos podido identificar a ¿quiénes hablan? y de ¿qué hablan?

Hasta aquí tenemos un cuadro descriptivo inicial que, tras un análisis más complejo de los datos, permite conocer los distintos discursos respecto al rol de China en un escenario de ascenso global, hegemonizado por Occidente y particularmente por Estados Unidos, donde existían más hipótesis que certezas.

\section{Resultados preliminares}

\subsection{Descripción general de los resultados de la muestra: descripción de la tabla general.}

Una vez constituido el corpus del análisis específico de la agenda, se logró identificar a 44 autores y 48 títulos, que representan el debate más citado acerca de la política internacional de China. Puesto en el Anexo de este trabajo, la información del corpus identifica autores/as, país de procedencia de la obra, filiación institucional de sus autores y demás referencias de los trabajos.

Con esta base general podemos esbozar el "mapa" de la discusión cuyo contenido debería ser la base para las siguientes investigaciones que podrían examinar aspectos más específicos de esta producción intelectual.

\subsection{Descripción y análisis de los autores (chinos y chinólogos)}

Los autores relevantes identificados en el análisis cuantitativo, permiten avanzar a un nivel de desagregación por países que nos brinda una mirada pormenorizada de la participación mundial del debate que nos interesa.

TABLA 1: Autores por país, 2000-2010

\begin{tabular}{|c|c|c|}
\hline \multirow[b]{2}{*}{ País } & \multicolumn{2}{|c|}{ Autores } \\
\hline & $\mathrm{N}^{\mathrm{o}}$ & $\begin{array}{l}\text { Ponderación } \\
(\%)\end{array}$ \\
\hline Alemania & 2 & 4,5 \\
\hline Australia & 3 & 6,8 \\
\hline Brasil & 1 & 2,3 \\
\hline Canadá & 1 & 2,3 \\
\hline China (Hong Kong) & 2 & 4,5 \\
\hline China (RPCh) & 5 & 11,4 \\
\hline Dinamarca & 2 & 4,5 \\
\hline Estados Unidos (EE.UU.) & 14 & 31,8 \\
\hline Francia & 1 & 2,3 \\
\hline
\end{tabular}




\begin{tabular}{|l|l|l|} 
Holanda & 1 & 2,3 \\
\hline Inglaterra & 3 & 6,8 \\
\hline Japón & 2 & 4,5 \\
\hline Singapur & 6 & 13,6 \\
\hline Suecia & 1 & 2,3 \\
\hline Total & $\mathbf{4 4}$ & $\mathbf{1 0 0 , 0}$ \\
\hline
\end{tabular}

Fuente: Elaboración propia sobre la base de información de Anexo.

Como puede apreciarse en la Tabla 1 de autores, la mayoría de ellos $(61,3 \%)$ está concentrado entre quienes trabajan en Estados Unidos $(31,8 \%)$ y quienes lo hacen en China o en un país de origen chino (Hong Kong y Singapur), que en conjunto representan el 29,5\% de la muestra. De los 14 intelectuales que trabajan en Estados Unidos, 6 de ellos son de origen chino. A ellos, como puede apreciarse en el Anexo, se agregan otros destacados intelectuales de origen chino que trabajan en diferentes lugares del mundo, como el destacado profesor Li Xing de la Aalborg University.

En consecuencia, sin perjuicio del lugar de trabajo, la producción acerca de la política internacional de China es, dominantemente, el debate entre intelectuales chinos, sin perjuicio que autores tan destacados como Barry Buzan sean parte de este "campo de fuerza".

Sin perjuicio de lo anterior, en el proceso de elaboración de este "mapa" del debate no se advierte la existencia de posiciones respecto de ser o no chino, sino que más bien respecto de tener o no el estatus de "intelectual-funcionario" o el de "intelectual-independiente". Hasta aquí, la revisión de este corpus tiende a inclinarnos a la conjetura de que la adhesión o distancia del gobierno de la República Popular de China es el factor crítico que ordena el debate general.

Llama la atención la baja presencia de autores de Japón y la inexistencia de autores de Taiwán y Corea del Sur, entre los más citados, a fin de que quedaran clasificados en el corpus seleccionado para este trabajo. La información examinada no nos permite elaborar conjeturas sólidas sobre este punto, pero su constatación es un aspecto resultante de la elaboración de este "mapa" que debería iluminar las indagaciones futuras.

Del mismo modo, pese a la presencia de unos pocos, aunque destacados autores, llama la atención la baja representación de la academia europea en la muestra. Las razones pueden ser variadas, no deja de sorprender que un continente que ha sido incapaz de competir económicamente con China, no esté elaborando una lectura propia sobre dicho proceso que, como hemos planteado, tiene un evidente correlato en su política internacional y en el desarrollo de sus cualidades estratégicas.

\subsection{Distribución de títulos por país de origen de las obras ${ }^{28}$}

Mirado desde los países de origen (Tabla 2), la producción intelectual acerca de la política internacional de China se concentra aún más en China, en términos generales. De los trabajos más citados, 27,1\% proviene de la República Popular de China, 4,2\% de Hong Kong y 8,3\% de Singapur.

Siguiendo el examen de concentración, la producción proveniente de Estados Unidos alcanza la misma que China con un 27,1\%.

\footnotetext{
${ }^{28}$ Artículos solos, en coautoría; libros como editores, coautores, autores, etc., de los lugares de publicación (países donde ocurre este debate).
} 
Muy correlativa con la distribución de la Tabla 1 de autores, la de títulos también ofrece una representación muy baja de trabajos de impacto (muy citados) elaborados en otros lugares del mundo, pese a que ellos se han visto afectados (positiva y negativamente) por el ascenso de China.

TABLA 2: Títulos por país, 2000-2010

\begin{tabular}{|l|l|l|}
\hline \multirow{2}{*}{ País } & \multicolumn{2}{|l|}{ Títulos } \\
\cline { 2 - 3 } & $\mathrm{N}^{\mathbf{0}}$ & Ponderación (\%) \\
\hline Alemania & 2 & 4,2 \\
\hline Australia & 2 & 4,2 \\
\hline Brasil & 1 & 2,1 \\
\hline Canadá & 1 & 2,1 \\
\hline China (Hong Kong) & 2 & 4,2 \\
\hline China (RPCh) & 13 & 27,1 \\
\hline Dinamarca & 2 & 4,2 \\
\hline Estados Unidos & 13 & 27,1 \\
\hline Francia & 1 & 2,1 \\
\hline Holanda & 1 & 2,1 \\
\hline Inglaterra & 3 & 6,3 \\
\hline Japón & 2 & 4,2 \\
\hline Singapur & 4 & 8,3 \\
\hline Suecia & 1 & 2,1 \\
\hline Total & $\mathbf{4 8}$ & $\mathbf{1 0 0 , 0}$ \\
\hline
\end{tabular}

Fuente: Elaboración propia sobre la base de información de Anexo.

Como en la tabla anterior, la representación de América Latina y el Caribe en este debate, con trabajo de impacto, es casi nula. En este caso ya no tiene que ver con la mayor o menor importancia del ascenso chino en nuestras realidades, como en el caso europeo, sino que se relaciona con la tradicional escasa participación de esta región en todos los debates internacionales. Quizá una excepción fue el período 1950-1980, con la llamada Escuela cepalino-dependentista, que sí logró permear ambientes intelectuales más allá del propio Continente.

\subsection{Ejes temáticos}

Como puede observarse en la Tabla 3, la discusión acerca de la política internacional de China, elaborada por intelectuales chinos y extranjeros (chinólogos), ofrece algunas tendencias bastante sólidas.

Una parte menor ocupa el análisis de la teoría de las relaciones internacionales. Como ya vimos, en China se hizo un esfuerzo por desarrollar teoría propia en un intento por desprenderse de la influencia de los enfoques elaborados en Estados Unidos, que en este país 
también habían adquirido una gran centralidad. El bajo número de trabajos de este tipo, parecería sugerir que los estudios sobre la política internacional de China han optado por estudiar aspectos mucho más concretos de la acción internacional de China y menos de las explicaciones abstractas en las que podría basarse dicha conducta.

Un lugar igualmente menor, relaciona la política internacional con la realidad nacional, cuestión que en una primera mirada podría parecer paradójica, dada la importancia que tradicionalmente se dio al factor ideológico y político del país, frente a todas las decisiones relevantes, entre las cuales, la política internacional ocupa un papel central, habida cuenta la apertura impulsada desde fines de la década de 1970 y considerando el rol que juega la internacionalización de China en su modelo de desarrollo.

Un lugar casi marginal es ocupado por temáticas como la globalización, la economía internacional, el multilateralismo y la cooperación. Todo indica que si bien constituyen aspectos relevantes del contexto mundial, subyace el supuesto de que la acción internacional de China depende más de su propia visión y acción, que de el ambiente internacional donde dicha política se expresa y practica.

Un lugar relevante lo ocupa el eje temático referido a la política exterior. El 55\% de los trabajos dedicados a este enfoque demuestra que la gran atención está puesta en describir, explicar y predecir la conducta internacional de China.

TABLA 3: Ejes Temáticos, 2000-2010

\begin{tabular}{|l|l|}
\hline TEMAS & Distribución (\%) \\
\hline Política Exterior & 55 \\
\hline Política Nacional & 17 \\
\hline Teoría de Relaciones Internacionales & 15 \\
\hline Globalización & 5 \\
\hline Economía Internacional & 4 \\
\hline Multilateralismo y Cooperación & 4 \\
\hline Total & 100 \\
\hline
\end{tabular}

Fuente: Elaboración propia, sobre la base de la información contenida en el Anexo.

Un examen detallado de la agenda de estudio/investigación de la política exterior china, demuestra ella tiene un alto grado de concentración en dos temas principales de un modo equilibrado: Poder y relaciones internacionales, que en conjunto explican más del $80 \%$ de la producción internacional.

Resulta muy interesante constatar que cuestiones como la seguridad, que en primera instancia podrían ser más importantes, aparecen en un lugar secundario. No obstante, también es coherente con el momento histórico del ascenso, que las cuestiones referidas al poder y a las relaciones internacionales asociadas a él tengan un lugar central. 
TABLA 4: China: Agenda de la Política Exterior

(2000-2010)

\begin{tabular}{|c|c|c|}
\hline \multicolumn{2}{|c|}{ Clasificación Principal } & \multirow[t]{2}{*}{ Clasificación Secundaria } \\
\hline Tema & Ponderación \% & \\
\hline Poder & 41 & $\begin{array}{ll}\text { - } & \text { Ascenso al poder } \\
\text { - } & \text { Inserción global del siglo XXI } \\
\text { - } & \text { Poder suave y poder diplomático } \\
\text { - } & \text { Nueva diplomacia } \\
\text { - } & \text { Orden regional }\end{array}$ \\
\hline $\begin{array}{l}\text { Relaciones } \\
\text { Internacionales }\end{array}$ & 40 & $\begin{array}{ll}\text { - } & \text { Relaciones regionales } \\
\text { - } & \text { Relaciones trans-regionales }\end{array}$ \\
\hline Seguridad & 7 & $\begin{array}{ll}\text { - } & \text { Cooperación } \\
\text { - } & \text { Globalidad } \\
\text { - } & \text { Economía } \\
\text { - } & \text { Cuestiones militares }\end{array}$ \\
\hline Otros & 12 & $\begin{array}{ll}\text { - } & \text { Recursos marinos } \\
\text { - } & \text { Política internacional } \\
\text { - } & \text { Cooperación internacional } \\
\text { - } & \text { Cuestiones domésticas } \\
& \text { Debilidades domésticas }\end{array}$ \\
\hline
\end{tabular}

Fuente: Elaboración propia, sobre la base de información contenida en el Anexo.

Como demuestra la Tabla 4, los temas que aparecen en la clasificación secundaria son referidos al relato específico de cómo, los autores/as estudiados, perciben los contenidos y los mecanismos para acceder y aumentar el poder, como para relacionarse con los otros países sin que este ascenso parezca amenazante. La conquista de la supremacía en un camino pacífico parece el paradigma más esencial de la política exterior de China y esa premisa de Sun-Tzu acerca de "ganar sin luchar" 29 , que de tanto repetida parecería ser una fantasía. Sin embargo, el enfoque que se deduce de esta producción intelectual más bien reafirma que tal idea prevalece en este pensamiento.

Al mismo tiempo, la estructura de esta agenda revela que para estos intelectuales China aún está en la fase de ascenso y conquista del lugar de supremacía, por lo que los análisis acerca de cómo llegar a ese punto y las relaciones que se deben establecer desde allí, son mucho más relevantes que los estudios acerca de cómo conservar ese lugar y/o cómo pensar ese lugar en términos abstractos.

El siempre central tema del poder, que en sus estudios ocupa el primer lugar (41\%), es conectado con temáticas subordinadas que dan cuenta el estatus aún no globalmente central de China. De allí, que hayan relacionado la cuestión del poder con el momento que el país vivía en la década analizada. En este sentido, el poder debería ser instrumental para ascender en la jerarquía internacional y ayudarles en su inserción global, que hasta aquí es principalmente económica y tal poder aún es visto con desconfianza en muchos países del mundo. Por ello

\footnotetext{
29 "El estratega vencedor, primero se asegura la victoria, después entra en combate" en: Sun-Tzu (2007): El Arte
} de la Guerra. Buenos Aires, Longseller. 
mismo, como ha demostrado Rodrigo Álvarez ${ }^{30}$, han estado indagando en la búsqueda de prestigio y legitimidad, para lo cual deben insistir en mostrarse como un "gigante amistoso", que evita la coacción y opta por el "poder suave". En tal sentido, insisten en destacar el nuevo rol y poder de la diplomacia, para proyectar una imagen positiva de su ascenso. Este enfoque ya está en marcha en el plano internacional, comenzando por el orden regional asiático, con la doble seducción china se presentarse como un socio comercial imprescindible y como una fuente financiera casi inagotable.

El tema de las relaciones internacionales ocupó el segundo lugar de las cuestiones principales $(40 \%)$, y aparece relacionado solo con dos temas subordinados: Relaciones regionales y relaciones trans-regionales. Los textos revelan que China concibe su proyección internacional desde su propia región, otorgándole un lugar central a su vínculo con los territorios que estuvieron bajo el control de Gran Bretaña y Estados Unidos, así como aquellos espacios -terrestres y marítimos- mediante los cuales extiende su influencia. En el plano extraasiático, lo que en los textos aparece denominado como relaciones trans-regionales, se refleja los estudios acerca de cómo conciben su rol global y sus relaciones con el resto del mundo, donde China se conceptualizaba no solo como líder del Tercer Mundo, sino que como un nuevo líder mundial, aunque aún en el tránsito a la cúspide.

El tema de la Seguridad, tercero en la jerarquía, pero muy debajo de los dos primeros (7\%): En consideración de cómo ha crecido la inversión china en Seguridad y defensa, este tema principal aparece subestimado el debate académico. En este sentido, China ha tenido éxito en desviar la atención académica del tema de la seguridad, como si se tratara de un país que hubiere perdido esa cualidad. Coherente con esta conjetura, en los estudios examinados la Seguridad aparece asociada a temas no convencionales, como cooperación, globalidad, economía y un genérico "cuestiones militares", tópicos que reflejaban la variedad de intereses asociados con la seguridad china, desde las temáticas tradicionales hasta las relacionadas con lo que desde 2003 se conocería como seguridad multidimensional.

Una multiplicidad y variedad de estudios que hemos catalogados en "otros" (12\%): Reflejan los demás temas de la agenda de intereses respecto de China, donde las cuestiones secundarias más recurrentes fueron cinco: Recursos marinos, política internacional, cooperación internacional, cuestiones domésticas y debilidades domésticas. Estas demuestran tanto la heterogeneidad propia de la política internacional de un país con pretensiones de potencia, como respecto de las capacidades internas efectivas para transformarse en el líder mundial que concebían los asesores y jerarcas políticos del gobierno chino.

En síntesis, la agenda de la política exterior de los autores enfocados en China revela que visualizan el ascenso de China en términos relativamente convencionales, tanto por el peso de la inercia disciplinar, algo que se repite en los estudios referidos a otros países, como a la naturaleza del proceso examinado, donde China ha ido ascendiendo gradualmente al poder reproduciendo un patrón muy similar al que han descrito otros casos de países que se transformaron en potencias de nivel mundial.

\section{Los efectos del ascenso en la política exterior de china}

\subsection{La fase del cambio}

La situación del ascenso transformó el auto-concepto internacional de China, desde concebirse como el líder del Tercer Mundo a aceptarse como un actor emergente en búsqueda de la supremacía.

\footnotetext{
30 Álvarez, Rodrigo (2017): La estrategia comunicacional de china hacia América del sur, Santiago: Ediciones Universidad Finis Terrae.
} 
Esta transformación mayor tensionó el discurso original, basado en la cooperación de la política exterior de China promovida, hasta entonces, por la estrategia de los 24 caracteres de Deng Xiaoping y la de los 16 caracteres de Jiang Zemin.

Los ataques del 9-11 a Estados Unidos, forzó a China a acelerar la incorporación de la supremacía, como un aspecto central de su nueva forma de auto-concebirse, lo que evidentemente implicó un proceso de re-significación internacional. En este contexto, y sin perder la idea del actor no invasivo y harmonioso, Hu Jintao debió re-articular, la política exterior de su país.

Procurando que este cambio no fuera percibido como radical, se impulsó una transformación de la política exterior basada en la acción multilateral. Con este enfoque China logró modificar su estatus, pasando desde una interacción cooperativa-hegemónica a una posición abiertamente co-hegemónica que facilitó su proceso en ascenso ${ }^{31}$ sin que él se viera abiertamente amenazante.

Como es obvio a esta altura, lo central era proyectar una visión de interacción global que minimizara la alta incertidumbre que estos cambios estaban produciendo en el mundo, reduciendo al máximo la duda que surgía sobre la articulación entre poder y rol global de China Por esto, Glaser y Murphy vieron que el poder emergente de China y el impacto futuro del mismo en la estabilidad internacional [estaba] entre los tópicos intensamente debatidos de sus relaciones internacionales. ${ }^{32}$

Con todo, para la mayoría de los observadores, se trataba de un cambio sutil en la estrategia china, cuyo rasgo más visible era su utilización de lo que algunos han visto como el uso del "poder blando". Por ejemplo, Li sostenía que los líderes de política internacional y expertos han dado una gran atención al crecimiento y práctica del "soft power" chino y han expresado sus preocupaciones por sus implicancias respecto a su impacto, considerando que se trataba de una forma de acceder a un nuevo status en un proceso de acomodo que no produjera inestabilidad o crisis innecesarias. ${ }^{33}$

Con este objetivo, la articulación y proyección de China, como un actor global, la política exterior china puso un fuerte énfasis a su acción diplomática, permitiendo encubrir/suavizar la tensión entre poder fuerte y blando, todo lo cual develaba que su verdadera estrategia, si queremos usar estos términos, era de "poder inteligente" (smart power), en la que China no centraba su acción en un solo atributo de su enorme poder, sino que estaba disponible para desplegar todo el menú, según fuera la necesidad del caso. Sin embargo, muchos autores quedaron seducidos por la noción del casi exclusivo uso del poder blando, en parte por el prestigio de esta idea de Joseph Nye Jr. y en parte porque la intelectualidad china, al reiterar en ese concepto, se ocupó de que las otras dimensiones de su poder tendieran a diluirse en los análisis referidos a su política exterior.

La velocidad del ascenso chino, sin embargo, hacía difícil que con una estrategia internacional de tipo poder blando, por bien diseñada que estuviera, lograra distraer a observadores expertos, sobre todo a los analistas del Departamento de Estado de los Estados Unidos. Como planteó Zhu Zhiqun de la Bucknell University, China [tenía] en cada una de las regiones del mundo, donde desarrollaba una diplomacia activa, intereses de múltiples niveles y

\footnotetext{
${ }^{31}$ Oviedo sostiene que en la dinámica de la historia contemporánea el ámbito de efectividad del sistema político chino presenta tres fases: contracción (1840-1943), transición a la expansión (1943-1955) y de expansión (19552001).

${ }^{32}$ Glaser, Bonnie y Murphy, Melissa (2009): "Soft power with Chinese characteristics: the ongoing debate", en Chinese Soft Power and its Implications for the United States Competition and Cooperation in the Developing World, Washington DC, Center for Strategic and International Studies, pp. 10-26

${ }^{33} \mathrm{Li}$, Xing (2010): The Rise of China and the Capitalist world order. New York, Routledge.
} 
propósitos; [donde principalmente estaba] mirando nuevos mercados para sus productos. ${ }^{34}$ Para Glaser y Murphy esta mayor presencia [podía] traducirse en que Beijing [quiera] promover los valores del socialismo Chino como una alternativa a los valores de Occidente, y [con ello] buscar promover asertivamente un modelo de desarrollo chino. ${ }^{35}$

\subsection{El debate en torno a la nueva política exterior}

La bibliografía examinada da cuenta detallada de cómo el ascenso de China le posicionó en el sistema internacional, en un contexto global multipolar, caracterizado por el movimiento doble planteado al comienzo de este trabajo. Sin embargo, planteó Li (2010), esto derivó en una visión competitiva de la relación entre China y Estados Unidos, cuestión que no fue eludida del todo por la política exterior china, basada en la estrategia de poder blando.

Para algunos autores menos indulgentes el ascenso chino es básicamente, un debate mundial sobre el futuro de los Estados Unidos y no sobre China. ${ }^{36}$ Esta afirmación revela un gran importante de confianza de una intelectualidad que no se plantea titubeante o con excesiva prudencia respecto del presente y futuro de su país. Muy notoriamente, estamos en un momento crucial de está transformación global.

Este optimismo desembozado tiene Yan Xuetong de la Tsinghua University, como su voz principal, quien relaciona el ascenso chino con la idea de rejuvenecimiento que según su visión se sustenta en dos ideas: En que el proceso de ascenso es uno que busca reconquistar el estatus internacional perdido y no como la obtención de un grado nuevo; y en que este proceso es considerado como una restauración justa, más que ganando ventajas sobre otros actores. ${ }^{37}$

Sin embargo, este renacer traía aparejado el dilema del Poder entre grandes actores. Shin Yinhong (2002) de la Renmin University of China, sostuvo que según las élites chinas y el público informado, se podrían dar tres escenarios en relación al ascenso de China en el contexto global: Aquellos que creen que entre Estados Unidos y China se dará un proceso de acomodación [y entendimiento] pero en un contexto de confrontación del tipo de Guerra Fría que podría incluir incluso conflictos mayores entre ambas naciones; aquellos que observan que se producirá una acomodación (entendimiento) entre Estados Unidos y China en la primera mitad del siglo veintiuno, pero que esta estará bajo sospechas mutuas, serias fricciones y quizás limitados conflictos que son inevitables o difíciles de evitar; y aquellos que creen en que se ocurrirá un inevitable conflicto mayor entre Estados Unidos y China, lo que se sucederá porque Estados Unidos nunca tolerará a China como un poder mundial o incluso como el segundo mayor poder en Asia y el Pacífico. Mucho antes de lo pensado por el profesor Yinhong, China no solo se convirtió en la segunda potencia en esta región del mundo, sino que en la segunda potencia del orbe.

En este dilema Michael A. Glosny del Massachusetts Institute of Technology observó que cualquiera fuera la categoría analítica en uso ("no-polaridad", "un mundo post americano" o "ascenso"), emerge una visión común en cuanto a que se trata de un proceso, o movimiento doble hemos planteado aquí, de reducción del poder e influencia de los Estados Unidos y el crecimiento del poder e influencia de los nuevos poderes emergentes con China a la cabeza. ${ }^{38}$

\footnotetext{
${ }^{34}$ Zhu, Liqun (2010): China's Foreign Policy Debates. Paris, Institute for Security Studies.

${ }^{35}$ Glaser y Murphy (2009), op.cit. p.13

${ }^{36}$ Muchie, Mammo y Li, Xing (2010): "The Myths and realities of the Rising Powers: Is China a Threat to the Existing World Order?", en The Rise of China and the Capitalist World Order, New York, Routledge, pp. 51-69.

${ }^{37}$ Xuetong, Yang: "The Rise of China in Chinese Eyes", Journal of Contemporary China, vol. 10, n²6, (agosto 2001), p. 33-39.

${ }^{38}$ Glosny, Michael: "China and the BRICs: A Real (but Limited) Partnership in a Unipolar World”, Polity ,vol. 42 n'1 (enero 2010), pp.100-129.
} 
Esta asunción motivó a que John J. Mearsheimer de la The University of Chicago, planteara más específicamente que el ascenso de China estaba teniendo un efecto significativo en el balance de poder global [;] en particular la distancia entre China y Estados Unidos se está reduciendo y probablemente la "supremacía estratégica" de los Estados Unidos en [la región del Asia-Pacífico] desaparecerá. ${ }^{39}$

En un pronóstico del futuro cercano, Xuetong sostuvo que era muy posible que China en los próximos 10 años alcance a los Estados Unidos económicamente y que en los próximos 20 años lo haga en términos militares. No podemos menos que afirmar que la dimensión económica Yan tuvo razón y que en la militar su visión pecó de exceso de optimismo. ${ }^{40}$

Por su parte, Li Xing y Steen Fryba Christensen, volviendo a la cuestión general, coincidieron con esta tensión y argumentaron que no hay dudas que China, como un poder en ascenso con un sostenido crecimiento económico y un creciente proceso de mayor fortaleza militar, tiene un gran interés por el Poder, que no puede siempre ser reconciliado con los intereses de otros Estados centrales en el orden liberal. El actual conflicto comercial, no es sino que una metáfora de la tensión general entre ambas potencias. ${ }^{41}$

Con todo, y pese a que la inserción global, fue utilizada hábilmente por China como una de sus herramientas de marketing internacional, mediante la estrategia de "integración armónica" y a través de la cooperación internacional, ella ha requerido del desarrollo de precondiciones internas críticas. A este respecto, en momentos diferentes, Shi planteó que la inserción y reconocimiento global de China requiere alcanzar tres objetivos nacionales fundamentales: Primero, una seguridad nacional básica; segundo, el mejoramiento de la calidad de vida de los chinos; y tercero, un posible status como poder mundial. ${ }^{42} \mathrm{El}$ mismo autor, ocho años más tarde, sostuvo que este proceso de interacción requería que China participara más intensamente en dos tipos de "plataforma": Regímenes de seguridad multilateral subregionales y organizaciones internacionales. ${ }^{43}$

Por otro lado, la profesora Alice Ba de la University of Virginia observó la importancia que tiene para China la profundización de sus relaciones regionales, lo que sería parte de su Política Exterior, donde se pone en relieve la prioridad del crecimiento económico y el interés de Beijing en tomar un papel más importante en las comunidades regionales y mundiales. ${ }^{44}$ Es este contexto, que implica desafíos de seguridad global, por lo que China, según Shi, estaba comprometida en una más amplia y profunda cooperación internacional. Ésta, vista como un medio de inserción global, puede tomar la forma de ayuda internacional. ${ }^{45}$ En esta línea argumental, Paul Opoku-Mensah, de la Norwegian University of Science and Technology, sostuvo que el reciente incremento en la actividad China dentro de la ayuda internacional, como

\footnotetext{
${ }^{39}$ Mearsheimer, John: "The Gathering Storm: China's Challenge to US Power in Asia", The Chinese Journal of International Politics, vol. 3, nº (diciembre 2010), pp. 381-396.

${ }^{40}$ Xuetong, Yang: "China's Rise and International Order [lecture]". Carnegie Endowment for International Peace, 7 de noviembre 2011

${ }^{41}$ Li, Xing y Fryba Christensen, Stenn (2012): The Rise of China the impact on semi-periphery and periphery countries. Aalborg, Denmark: Aalborg University Press.

${ }^{42}$ Shi, Yinhong: "The Rising China: Essential Disposition, Secular Grand Strategy, and Current Prime Problems". Asian Voices: Promoting Dialogue Between the US and Asia [working paper], febrero 2002.

43 ibid.

${ }^{44} \mathrm{Ba}$, Alice: "China and ASEAN: Re-navigating Relations for a 21st Century Asia”, Asian Survey, vol. 43, n4 (julio-agosto 2003), pp. 622-647.

${ }^{45}$ Shi, Yinhong: "Universal Norms and China's Complexity in Addressing "Global” Security Challenges", Lecture Series 2010-2011 'Global Values in a Changing World', 18 de abril de 2011
} 
en muchas áreas del sistema internacional, está elevando una permanente preocupación desde Occidente acerca del rol e impacto en este sistema internacional de poder y desarrollo. ${ }^{46}$

Como se planteó antes, en términos más abstractos, en este contexto de ascenso chino ante la constatación preocupada de las demás potencias mundiales, China ha desplegado una estrategia que muchos autores no chinos y la mayoría de los chinos ha denominado, a nuestro juicio de manera incompleta, como de Poder Blando. Las razones por las que creemos más en el Inteligente y no en el Poder Blando ya han sido expuestas, pero lo relevante en este punto de un artículo como éste es constatar el curso de un debate que ha optado por la primera de estas categorías. En él, el Poder Blando y Diplomático hace referencia a un país que asciende en armonía, centrando su acción internacional en la cooperación y en un comercio que hace una parte muy central del crecimiento mundial de las últimas dos décadas.

Los observadores internos y críticos del proceso vivido por esta potencia ascendente, sin embargo, ven este proceso con preocupación, por cuanto advierten la igualmente creciente resistencia a China. Por ello, optan por la prudencia del gradualismo, proponiendo contener y suavizar el proceso, amparados en una política exterior que ejerza el poder blando y en una diplomacia que lidere esta forma más amable de interactuar internacionalmente, también para mejorar la aproximación regional y global del país.

En esta lógica se inscribe la idea del profesor Xintian Yu, que planteó que el mundo tiene tres expectativas del poder blando chino: primero, que China elija un camino pacífico en su proceso de ascenso y resuelva pacíficamente las demanda por Taiwán; segundo, que explore caminos de colaboración y de "ganar-ganar" en el mercado mundial; y tercero, que trabaje más responsablemente en los temas internacionales y contribuya más con los bienes públicos, incluyendo pensamientos creativos, propuestas, mecanismos y la construcción institucional sustenta en la sabiduría china. ${ }^{47}$

Así, el discurso del Poder Blando, se convirtió en el bálsamo de su acomodo internacional y por ello para la política china ha sido clave difundir esta idea por todo el mundo. A este respecto, para Glaser y Murphy el Poder Blando chino ha estado dominado por dos escuelas: Una, de sociólogos y filósofos, que sostiene que el núcleo de este poder es cultural; y otra, compuesta por algunos expertos de las relaciones internacionales, que sin negar la importancia de la variable cultural, se centraron en examinar cómo se utilizaron los recursos de poder blando, concluyendo que el poder político es el núcleo del Poder Blando. ${ }^{48}$ Parafraseando a Zhang Bao-hui, en años recientes China ha puesto una gran energía en el análisis de cómo este Poder ${ }^{49}$ puede promover su influencia regional y mundial. ${ }^{50}$

Sin embargo, no existe una posición única sobre el potencial del desarrollo del Poder Blando chino como parte de su Política Exterior. Por ejemplo, Li observó que la corriente principal de la evaluación del estado del poder-blando de China hecha por los analistas chinos es que éste es todavía un eslabón débil en la búsqueda que hace China por un mayor poder internacional, por lo que esta variable se ha quedado muy atrás respecto de la referida al crecimiento del Poder Duro. ${ }^{51}$ En esta misma línea, como una evaluación de balance de poder,

\footnotetext{
${ }^{46}$ Opoku-Mensah, Paul (2010): “China and the International Aid System: Transformation or Cooptation?", en The Rise of China and the Capitalist World Order. New York, USA: Ashgate Publishing Limited.

${ }^{47}$ Yu, Xintian: "The Role of Soft Power in China's External Strategy", Guoji Wenti Yanjiu, 13 de marzo 2008.

${ }^{48}$ Glaser y Murphy (2009), op. cit. p.13.

${ }^{49}$ Que incluye recursos culturales e ideológicos, por un lado, e incentivos económicos y financieros por el otro.

${ }^{50}$ Zhang, Baohui: "Chinese Foreign Policy in Transition: Trends and Implications", Journal of Current Chinese Affairs, vol.39, n'2 (2010), p.39-68.

${ }^{51} \mathrm{Li}$ (2010), op. cit. p.13.
} 
Xuetong vio que frente al enorme aumento del poder material de China, el incremento de su Poder Blando aún resulta insuficiente. ${ }^{52}$

Para el profesor Zhu Zhiqun la nueva diplomacia poseía 4 variables a considerar: Uno, diplomacia de buen vecino; dos, diplomacia de gran poder; tres, diplomacia energética; y cuatro, diplomacia pública. Todas ellas como piezas clave para alcanzar los mayores objetivos de la Política Exterior del Partido de la República Popular China, lo que estaría orientado a desarrollarla como un mayor poder económico, político, cultural y militar hacia la mitad del siglo veintiuno. ${ }^{53}$

La Nueva Diplomacia y Orden Regional estuvieron orientadas a la proyección de la política exterior de China nivel regional. Los trabajos a este respeto anticipaban que esta nueva diplomacia debía articularse con los cambios regionales que se experimentarían. ${ }^{54}$

Para Zhang, ${ }^{55}$ la visión de China sobre su propio rol en el orden regional ha, últimamente sufrido grandes cambios. Hasta hace poco la discusión en el país era sobre cómo estar envuelta en el mundo con las instituciones regionales de cooperación existentes. Sin embargo, ahora con el ascenso de poder y confianza, China ha estado trabajando para tener un mayor liderazgo regional e incluso remodelando el orden regional. Para este autor, habían 5 características de la nueva postura de la política exterior China que coadyuvarían al despliegue de esta nueva diplomacia: primero, una completa amistad con los Estados Unidos en una nueva relación bilateral, que como vemos es una tarea de suyo compleja; segundo, una creciente tendencia de un suave balance en las grandes relaciones de poder, que está representada por una profundización de las relaciones estratégicas con Rusia; tercero, un esfuerzo por re-modelar los órdenes de múltiples regiones en mundo, incluyendo aquellas que están afuera del contexto natural geográfico del Este-Asiático, tal como África y Asia Central; cuarto, una estrategia de seguridad económica global que ha contribuido al impacto y presencia mundial de China; y quinto, la búsqueda del Poder Blando, una mezcla de diplomacia económica y apelaciones ideológicas y culturales, así como de promover la influencia global y regional de China.

Respecto de las relaciones regionales y trans-regionales, se ha desarrollado una posición orientada hacia un proceso evolutivo sobre la visión que China, respecto a su autarquía e interacción global. Así, el objetivo central de la primera década del siglo veintiuno es resolver y aprender a interactuar sobre la tensión histórica y permanente que existía entre China y su entorno geográfico y geopolítico de influencia directa, donde el resurgimiento del "nacionalismo" es visto como un problema central.

Para Yinan He (2007) de la Lehigh University, quien analiza las relaciones ChinoJaponesas, este es un problema estructural donde el sentimiento nacionalista visceral tiene raíces profundas en décadas de educación escolar centralizada y de propaganda oficial china, la que implementó mitos perniciosas en la memoria colectiva nacional. Lora Saalman de la Stockholm International Peace Research Institute, refiriéndose a la relación Chino-India, sostenía que las relaciones internacionales chinas se ven determinadas también por terceros actores, razón por la cual la disparidad provocada por el levantamiento de las sanciones a la India sobre el embargo de armas, por Estados Unidos y la Unión Europea, pero que permanece

\footnotetext{
${ }^{52}$ Xuetong, Yang: "The Path for China to Increase its "Soft Power", China and World Affairs, vol. 2, n'1 (abril (2006), p. 1-3.

${ }^{53}$ Zhu (2010). op. cit. p.14.

${ }^{54}$ Zhang (2010). op. cit. p. 17.

${ }^{55}$ Ibid.
} 
sobre China, ha provocado que las percepciones, sobre todo de China, estén experimentado una serie de cambios tanto perceptibles como imperceptibles. ${ }^{56}$

Desde una perspectiva de la relación Sino-ASEAN, Ba observó que dado los cambios de la estrategia post-guerra fría de los Estados Unidos en el Sudeste Asiático, se ha focalizado principalmente sobre las implicancias de la modernización militar china y sus actividades en el Mar de China Meridional. Estas tensiones regionales hicieron que Shi (2010) observara que China debe avanzar en una seguridad cooperativa multilateral, la que implica una gran estrategia caracterizada por cinco puntos: Uno, diplomacia bilateral clásica o tradicional; dos, crear, fomentar, consolidar y desarrollar instituciones de seguridad multilateral sub-regional y regional; tres, ayudar a la estabilidad y seguridad regional, a través de la promoción de interdependencia económica y por la integración económica regional y sub-regional; cuatro, promoción de un intercambio humano y cultural entre los pueblos y; cinco, desarrollar y extender un "gran poder coordinado". 57

La idea de la cooperación regional es también sustentada por Zhu Liqun de la European Union Institute for Security Studies (EUISS), que sostiene que regionalmente el comportamiento de China está caracterizado por intentos permanentes de participar en una cooperación regional más que tratar de re-modelar la estructura de poder regional por medio de la coerción. En la vereda opuesta a Zhu Liqun se encuentra Mearsheimer que ha sostenido que los vecinos de China en la región del Asia-Pacífico están preocupados por el ascenso chino, cuyo rasgo principal observable es su pretensión de hegemonía regional y, muy probablemente alcanzar la posición que le permita alterar la distribución regional del poder.

La visión trans-regional de influencia directa de China tuvo como finalidad equilibrar los conceptos de cooperación y competencia; focalizándose en las relaciones con Estados Unidos, África y Latinoamérica. De este modo, para el caso de las relaciones China-EEUU, estás fueron conducidas por el concepto de coo-petition ${ }^{58}$; la que lograba articular la dualidad entre cooperación y competencia. Esta relación entre ambas naciones, según Shi, se da en un contexto en el cual existe una estructura de poder básica en el mundo, la que se caracteriza por la preponderancia de Estados Unidos y la comunidad occidental de naciones con el primero de ellos como líder. ${ }^{59}$

Sin embargo, para Zhang, el ascenso de China -como una potencia global, está teniendo un impacto profundo sobre las relaciones con Estados Unidos. Para él esta relación ha sido redefinida y aunque China aún persigue una estrategia de cooperación, ésta también ha llegado a ser más firme en su relación con este país. En tal sentido, Steve Chan de la University of Colorado ve el proceso chino de relaciones internacionales a través de la teoría de transición de poder, donde la relación China-EEUU está enmarcada en dos visiones: China como amenaza y China no es un poder status quo ${ }^{60}$ Xuetong y Qi Haixia analizan el significado y potencialidad de las actuales relaciones China-Estados Unidos, caracterizadas por lo que ellos denominan "amigos superficiales", lo cual implica un estado de relaciones bilaterales también como estratégicas. ${ }^{61}$ Mearsheimer desde una visión de competencia Chino-EEUU, espera que China se comporte de la forma en que Estados Unidos ha actuado durante su larga historia; en

\footnotetext{
56 Saalman, Lora: 'Between 'China Threat Theory' and 'Chindia': Chinese Responses to India's Military Modernization”, The Chinese Journal of International Politics ,vol. 4, nº1 (marzo 2011), p. 87-114.

${ }^{57}$ Shi (2011), op. cit. p.16.

${ }^{58}$ Colaboración entre competidores de negocios, con la esperanza de resultados mutuamente beneficiosos.

${ }^{59}$ Shi (2002), op. cit. p. 15.

${ }^{60}$ Chan, Steve (2008): China, the U.S., and the Power- Transition Theory: A Critique. New York, Routledge.

${ }^{61}$ Xuetong, Yang y Haixia, Qi: How to Avoid a U.S.-China Cold War. The Diplomat, 25 de septiembre de 2012.
} 
concreto, cree que China tratará de dominar la región de Asia-Pacífico más de lo que Estados Unidos domina el hemisferio occidental.

En una línea similar se plantea Jing-dong Yuan, argumentando que los elementos clave de la Doctrina Bush, tal como prevención, defensa de misiles y el crecimiento de la presencia militar de los Estados Unidos como resultado de la guerra contra el terrorismo, afectan directamente a los intereses de la seguridad nacional china. ${ }^{62}$ En los casos de África y América Latina, los análisis se orientan al Poder Blando que China está desarrollando en estas regiones, principalmente por la vía de la ayuda económica e inversiones. Según Li, la relación ChinoÁfrica no es nueva y ésta puede ser resumida en tres etapas: Entre 1940 y 1970, período caracterizado por el uso de la ayuda como una herramienta moral, ideológica y de política exterior que tenía el objetivo de ser usada por China para apoyar a otros países socialistas y movimientos de liberalización; entre 1978 y 1989, marcada por el fin de la promoción ideológica y por el comienzo del pragmatismo económico, pero que significo un declive en la ayuda a África y el tercer período, que comienza post-Tiananmen en donde se desarrolla una incomparable relación institucionalizada.

\section{Conclusión}

A modo de conclusión, y teniendo en cuenta que el propósito central de este trabajo es configurar una especie de mapa de la agenda china de los estudios internacionales (quiénes son y de qué hablan), hemos llegado a cinco ideas principales, que sintetizan tanto el sentido de este análisis, la metodología utilizada para este efecto, como sus principales resultados vertidos en las ideas y en la política exterior de China, en la década de ascenso más dinámico (2000-2010). Primero, respecto del contexto del movimiento doble, donde surgieron las tensiones que dieron lugar a la observación y a la indagación de este trabajo; segundo, respecto de los enfoques utilizados para abordar el proceso de asenso de China; tercero, en cuanto al método que hemos empleado para reconstruir la agenda de discusión; cuarto, respecto de los resultados arrojados por la aplicación de la metodología en el corpus seleccionado; y quinto, acerca del impacto de este debate en la política exterior de China en el período de ascenso.

En cuanto a lo primero, y como se ha planteado en este trabajo, las transformaciones mundiales de los últimos 40 años y los resultados obtenidos por China y Estados Unidos en dicho proceso, han detonado un movimiento doble que ha descrito la declinación gradual de Estados Unidos y el ascenso acelerado de China. Esto ha implicado un debate muy intenso acerca de las consecuencias de esta transformación, yendo desde las observaciones obvias a los cambios en el comercio mundial hasta dimensiones menos visibles, como es preguntarnos tanto por quienes producen las ideas, como por las ideas mismas que sostienen este impulso ascendente. Preguntarse por estos intelectuales-funcionarios, por sus obras y por su visión del mundo, constituye un ejercicio complejo que la Historia de las Ideas y la Historia Intelectual ha realizado tradicionalmente y que, da tanto repetido, lo damos por sentado, sobre todo para el mundo Occidental, esencialmente porque ahí residió el centro del mundo desde la Antigüedad. Como sabemos, ese eje se movió desde el Atlántico hasta el Pacífico, pero no solo desde el punto de vista productivo, sino que desde la perspectiva del poder. Esta dimensión nos obliga a remitirnos a la reflexión de fondo, respecto del o los paradigmas que guían tales ideas.

Respecto de lo segundo, ha sido clave para este trabajo y para otros de su misma naturaleza, haber incorporado los enfoques en uso durante la primera década del siglo veintiuno, que estuvieron centrados en identificar y caracterizar el trabajo de los centros de pensamiento y las teorías de Relaciones Internacionales en debate. Estos trabajos pusieron menos interes en identificar a los expertos chinos y chiólogos, especialmente respecto de aquellos que tanto

${ }^{62}$ Yuan, Jing-dong: "The Bush Doctrine: Chinese Perspective and Responses”, Asian Perspective, vol. 27, $\mathrm{n}^{\circ} 4$, (2003), p.111-145. 
examinaron como promovieron las tesis acerca del ascenso del país. Como hemos señalado más arriba, nuestra conjetura es que esto último, ocurrió quizá porque la urgencia residía en develar la estrategia política china y para ello conocer el grado de compromiso estatal y disciplinario de los centros de investigación gubernamentales y universitarios era fundamental.

En todo este proceso, la identificación de chinos influyentes fue posible a partir del estudio de los think tanks y de las revistas científicas. Una revisión de las publicaciones sobre estas fuentes nos informa acerca del lugar de pertenencia y de las dificultades teóricas, pero menos respecto a ¿quiénes y de qué hablan? lo cual ha sido posible a través de la metodología de la agenda de estudios, planteada en este trabajo.

Como tercera conclusión, y para los efectos de reconstruir la agenda de estudio, se usó la metodología desarrollada por uno de los autores de este trabajo, para lo que se seleccionó una lista de autores y obras clave, a partir de lo cual se identificó los temas de la agenda de estudios. Sobre esa base se reconstruyó la estructura y los énfasis del debate.

Como cuarta conclusión, y una vez constituido el corpus del análisis específico de la agenda, se logró identificar a 44 autores y 48 títulos, que representan el debate más citado acerca de la política internacional de China.

A partir de ahora ya sabemos que la discusión acerca de China se concentró en la Política Exterior de este país en más de un 50\%, que sobre política nacional se enfocó un $17 \%$, que sobre teoría de las relaciones internacionales un $15 \%$, relegando a no más de un $5 \%$ nominal, a cuestiones como globalización, economía internacional y multilateralismo y cooperación.

Con esta base general hemos podido esbozar el "mapa" de la discusión, cuyo contenido debería ser la base o la guía para las investigaciones venideras, cuyos propósitos podrán profundizar sobre aspectos más específicos de esta producción intelectual.

Centrando la observación en el la política exterior, tema que concentra la agenda, constatamos que en ella solo dos cuestiones ocupan más del $80 \%$ de la atención: el poder y las relaciones internacionales. Dentro de estos dos ejes centrales, las cuestiones específicas denotan que la prioridad transversal tiene relación con el posicionamiento hegemónico de China, lo que se revela en la agenda específica cuyos temas fueron: Ascenso al poder, inserción global del siglo XXI, poder suave y poder diplomático, nueva diplomacia, orden regional, relaciones regionales y relaciones trans-regionales.

La centralidad del tema del poder ocupa el primer lugar (41\%), es conectado con temáticas subordinadas que dan cuenta el estatus de supremacía creciente de China. En esta agenda el poder ocupa un papel instrumental para ascender en la jerarquía internacional y ayudarles en su inserción global, que hasta aquí es principalmente económica y tal poder aún es visto con desconfianza en muchos países del mundo.

Por su parte, el tema de las relaciones internacionales ocupó el segundo lugar de las cuestiones principales (40\%), y aparece relacionado solo con dos temas subordinados, como son las relaciones regionales y relaciones trans-regionales. Los textos revelan que China concibe su proyección internacional desde su propia región. En el plano extra-asiático, lo que en los textos aparece denominado como relaciones trans-regionales, se refleja los estudios acerca de cómo conciben su rol global y sus relaciones con el resto del mundo, donde China se conceptualizaba no solo como líder del Tercer Mundo, sino que, como un nuevo líder mundial, aunque aún en el tránsito a la cúspide.

En una posición muy marginal (7\%), se sitúa el tema de la Seguridad. Esta posición contrasta con el tamaño de la inversión china en Seguridad y defensa, lo que en el debate académico aparece muy subestimado. 
Por último, registramos una variedad de estudios con una multiplicidad de intereses que hemos catalogados en "otros" (12\%), donde se resaltan 5 tópicos: Recursos marinos, política internacional, cooperación internacional, cuestiones domésticas y debilidades domésticas.

En síntesis, como plateamos más arriba, la agenda de la política exterior de los autores enfocados en China indica que ellos observan el ascenso de China en términos relativamente convencionales, tanto por el peso de la inercia disciplinar, como a la naturaleza del proceso examinado, donde China ha ido escalando gradualmente en la jerarquía mundial del poder, reproduciendo un patrón muy similar al que han descrito otros casos de países que se transformaron en potencias de nivel mundial.

A partir de estos hallazgos, no solo se refuerza la tesis acerca de la búsqueda china de conquistar la supremacía a través en un camino pacífico, sino que se establece una hoja de ruta muy precisa las futuras investigaciones.

Como quinta y última conclusión, observamos que, en la lectura detallada de los autores principales, se advierte una importante convergencia respecto de que el ascenso de China transformó el auto-concepto del lugar del país en el escenario internacional. China pasó de concebirse como el líder del Tercer Mundo a verse a sí misma como un actor emergente en búsqueda de la supremacía.

Como hemos planteado, en las páginas anteriores, en el debate examinado constatamos que estas transformaciones mayores tensionaron el discurso internacionalista original, basado en la cooperación de la política exterior de China promovida por las doctrinas de Deng Xiaoping y de Jiang Zemin.

Observamos, así mismo, que los ataques del 9-11 (2001) aceleraron aún más la transformación del rol internacional de China, asumiendo más claramente su papel de potencia, tarea que corresondió a Hu Jintao.

En este contexto, e intentando que en este nuevo estatus China no fuera vista como una amenaza, se impulsó una renovada política multulateral, donde lo central fue pasar desde una interacción cooperativa-hegemónica a una posición abiertamente co-hegemónica, que facilitó su proceso en ascenso. En este camino, sin embargo, China no pudo evitar aparecer como una amenaza emergente para la supremacía unilateral de Estados Unidos. 
ANEXO

\begin{tabular}{|c|c|c|c|c|c|c|}
\hline $\mathbf{N}^{\mathbf{o}}$ & $\begin{array}{l}\text { AUTORAS/ } \\
\text { ES }\end{array}$ & $\begin{array}{l}\text { PUBLICAC } \\
\text { IÓN }\end{array}$ & AÑO & TÍTULO & $\begin{array}{l}\text { INSTITUCIÓN } \\
\text { ADSCRITA/O }\end{array}$ & PAÍS \\
\hline 1 & Ba, Alice D. & Asian Survey & 2003 & $\begin{array}{l}\text { China and ASEAN: } \\
\text { Re-navigating } \\
\text { Relations for a } 21^{\text {st }} \\
\text { Century Asia }\end{array}$ & $\begin{array}{l}\text { University of } \\
\text { Virginia }\end{array}$ & $\begin{array}{l}\text { Estados } \\
\text { Unidos }\end{array}$ \\
\hline 2 & Buzan, Barry & $\begin{array}{l}\text { The Chinese } \\
\text { Journal of } \\
\text { International } \\
\text { Politics }\end{array}$ & 2010 & $\begin{array}{l}\text { China in International } \\
\text { Society: Is 'Peaceful } \\
\text { Rise' Possible? }\end{array}$ & $\begin{array}{l}\text { London School } \\
\text { of Economics }\end{array}$ & Inglaterra \\
\hline 3 & Chan, Steve & Routledge & 2008 & $\begin{array}{l}\text { fChina, the U.S., and } \\
\text { the Power-Transition } \\
\text { Theory: A critique }\end{array}$ & $\begin{array}{l}\text { University of } \\
\text { Colorado }\end{array}$ & $\begin{array}{l}\text { Estados } \\
\text { Unidos }\end{array}$ \\
\hline 4 & Chou, Mark & $\begin{array}{l}\text { Australian } \\
\text { Review of } \\
\text { Public } \\
\text { Affairs }\end{array}$ & 2011 & $\begin{array}{l}\text { Theorising China's } \\
\text { international Relations }\end{array}$ & $\begin{array}{l}\text { Universidad de } \\
\text { Melbourne }\end{array}$ & Australia \\
\hline 5 & $\begin{array}{l}\text { Choy, } \\
\text { Howard } \\
\text { Yuen Fung }\end{array}$ & Brill & 2008 & $\begin{array}{l}\text { Remapping the Past } \\
\text { Fictions of History in } \\
\text { Deng's China, 1979- } \\
1997\end{array}$ & $\begin{array}{l}\text { Wittenberg } \\
\text { University }\end{array}$ & $\begin{array}{l}\text { Estados } \\
\text { Unidos }\end{array}$ \\
\hline 6 & $\begin{array}{l}\text { Chung, } \\
\text { Chien-peng }\end{array}$ & Routledge & 2010 & $\begin{array}{l}\text { China's multilateral } \\
\text { cooperation in Asia } \\
\text { and the Pacific : } \\
\text { institutionalizing } \\
\text { Beijing's "good } \\
\text { neighbour policy"63 }\end{array}$ & $\begin{array}{l}\text { Lingnan } \\
\text { University }\end{array}$ & $\begin{array}{l}\text { China } \\
\text { (Hong- } \\
\text { Kong) }\end{array}$ \\
\hline 7 & $\begin{array}{l}\text { Douglass, } \\
\text { Patrick }\end{array}$ & $\begin{array}{l}\text { School of } \\
\text { Advanced } \\
\text { International } \\
\text { Studies } \\
\text { [Working } \\
\text { paper] }\end{array}$ & 2009 & $\begin{array}{l}\text { Public Opinion's New } \\
\text { Role in Chinese } \\
\text { Foreign Policy }\end{array}$ & $\begin{array}{l}\text { Johns Hopkins } \\
\text { University }\end{array}$ & $\begin{array}{l}\text { Estados } \\
\text { Unidos }\end{array}$ \\
\hline 8 & $\begin{array}{l}\text { Ford, } \\
\text { Christopher } \\
\text { A. }\end{array}$ & $\begin{array}{l}\text { Hudson } \\
\text { Institute }\end{array}$ & 2012 & $\begin{array}{l}\text { "Occupy Wall Street" } \\
\text { and Communist } \\
\text { China's Emerging } \\
\text { "Neo-Kong" Discourse } \\
\text { of Antidemocratic } \\
\text { Legitimacy }\end{array}$ & $\begin{array}{l}\text { Serves as } \\
\text { Assistant } \\
\text { Secretary of State } \\
\text { for International } \\
\text { Security and } \\
\text { Non- } \\
\text { Proliferation. }\end{array}$ & $\begin{array}{l}\text { Estados } \\
\text { Unidos }\end{array}$ \\
\hline 9 & $\begin{array}{l}\text { Glaser } \\
\text { Bonnie S. y } \\
\text { Murphy, } \\
\text { Melissa E. }\end{array}$ & CSIS & 2009 & $\begin{array}{l}\text { Soft power with } \\
\text { Chinese } \\
\text { characteristics: the } \\
\text { ongoing debate }^{64}\end{array}$ & $\begin{array}{l}\text { Center for } \\
\text { Strategic and } \\
\text { International } \\
\text { Studies }\end{array}$ & $\begin{array}{l}\text { Estados } \\
\text { Unidos }\end{array}$ \\
\hline
\end{tabular}

${ }^{63}$ Chung, C. P. (2010). China's multilateral cooperation in Asia and the Pacific: Institutionalizing Beijing's "good neighbour policy". New York: Routledge.

${ }^{64}$ En McGiffert, (2009), op, cit, p.13 


\begin{tabular}{|c|c|c|c|c|c|c|}
\hline 10 & He, Yinan & $\begin{array}{l}\text { Journal of } \\
\text { Contemporar } \\
\text { y China }\end{array}$ & 2007 & $\begin{array}{l}\text { History, Chinese } \\
\text { Nationalism and the } \\
\text { Emerging Sino - } \\
\text { Japanese Conflict }\end{array}$ & $\begin{array}{l}\text { Lehigh } \\
\text { University }\end{array}$ & $\begin{array}{l}\text { Estados } \\
\text { Unidos }\end{array}$ \\
\hline 11 & $\begin{array}{l}\text { Inoguchi, } \\
\text { Takashi }\end{array}$ & $\begin{array}{l}\text { The Chinese } \\
\text { Journal of } \\
\text { International } \\
\text { Politics }\end{array}$ & 2010 & $\begin{array}{l}\text { World Order Debates } \\
\text { in the Twentieth } \\
\text { Century: Through the } \\
\text { Eyes of the Two-level } \\
\text { Game and the Second } \\
\text { Image }\end{array}$ & $\begin{array}{l}\text { University of } \\
\text { Tokyo }\end{array}$ & Japón \\
\hline 12 & $\begin{array}{l}\text { Jiang, } \\
\text { Xiyuan }\end{array}$ & $\begin{array}{l}\text { International } \\
\text { Review }\end{array}$ & 2006 & $\begin{array}{l}\text { Theoretical Norms of } \\
\text { Transformation of } \\
\text { International System } \\
\text { and China's Choices }\end{array}$ & $\begin{array}{l}\text { Shangai Institute } \\
\text { for International } \\
\text { Studies }\end{array}$ & China \\
\hline 13 & $\begin{array}{l}\text { John J. } \\
\text { Mearsheimer }\end{array}$ & $\begin{array}{l}\text { The Chinese } \\
\text { Journal of } \\
\text { International } \\
\text { Politics }\end{array}$ & 2010 & $\begin{array}{l}\text { The Gathering Storm: } \\
\text { China's Challenge to } \\
\text { US Power in Asia }\end{array}$ & $\begin{array}{l}\text { The University } \\
\text { of Chicago }\end{array}$ & $\begin{array}{l}\text { Estados } \\
\text { Unidos }\end{array}$ \\
\hline 14 & $\begin{array}{l}\text { Kjeld Erik } \\
\text { Brødsgaard y } \\
\text { Zheng, } \\
\text { Yongnian }\end{array}$ & Routledge & 2006 & $\begin{array}{l}\text { The Chinese } \\
\text { Communist Party in } \\
\text { Reform }\end{array}$ & $\begin{array}{l}\text { Copenhagen } \\
\text { Businees School } \\
\text { National } \\
\text { University of } \\
\text { Singapore }\end{array}$ & $\begin{array}{l}\text { Dinamarca } \\
\text { Singapore }\end{array}$ \\
\hline 15 & Lai, Hongyi & $\begin{array}{l}\text { Palgrave } \\
\text { Macmillan }\end{array}$ & 2006 & $\begin{array}{l}\text { Reform and the Non- } \\
\text { State Economy in } \\
\text { China } \\
\text { The Political Economy } \\
\text { of Liberalization } \\
\text { Strategies }\end{array}$ & $\begin{array}{l}\text { University of } \\
\text { Nottingham }\end{array}$ & Inglaterra \\
\hline 16 & $\begin{array}{l}\mathrm{Li}, \\
\text { Mingjiang }\end{array}$ & $\begin{array}{l}\text { Lexington } \\
\text { Books }\end{array}$ & 2009 & $\begin{array}{l}\text { Soft Power China's } \\
\text { Emerging Strategy in } \\
\text { International Politics }\end{array}$ & $\begin{array}{l}\text { Nanyang } \\
\text { Technological } \\
\text { University }\end{array}$ & Singapore \\
\hline 17 & $\begin{array}{l}\text { Li, } \\
\text { Mingjiang } \\
\text { Kwa, Chong } \\
\text { Guan }\end{array}$ & $\begin{array}{l}\text { World } \\
\text { Scientific } \\
\text { Pub Co. Inc. }\end{array}$ & 2011 & $\begin{array}{l}\text { China-asean sub- } \\
\text { regional cooperation: } \\
\text { Progress, problems } \\
\text { and prospect }\end{array}$ & $\begin{array}{l}\text { Nanyang } \\
\text { Technological } \\
\text { University }\end{array}$ & Singapore \\
\hline 18 & Li, Xing & Routledge & 2010 & $\begin{array}{l}\text { The Rise of China and } \\
\text { the Capitalist world } \\
\text { order }\end{array}$ & $\begin{array}{l}\text { Aalborg } \\
\text { University }\end{array}$ & Dinamarca \\
\hline 19 & $\begin{array}{l}\text { Li, Xing y } \\
\text { Steen Fryba } \\
\text { Christiansen }\end{array}$ & $\begin{array}{l}\text { Aalborg } \\
\text { University } \\
\text { Press }\end{array}$ & 2012 & $\begin{array}{l}\text { The Rise of China the } \\
\text { impact on semi- } \\
\text { periphery and } \\
\text { periphery countries }\end{array}$ & $\begin{array}{l}\text { Aalborg } \\
\text { University }\end{array}$ & Dinamarca \\
\hline 20 & $\begin{array}{l}\text { Lora } \\
\text { Saalman }\end{array}$ & $\begin{array}{l}\text { The Chinese } \\
\text { Journal of } \\
\text { International } \\
\text { Politics }\end{array}$ & 2011 & $\begin{array}{l}\text { Between 'China } \\
\text { Threat Theory' and } \\
\text { 'Chindia': Chinese } \\
\text { Responses to India's }\end{array}$ & $\begin{array}{l}\text { Stockholm } \\
\text { International } \\
\text { Peace Research } \\
\text { Institute (SIPRI) }\end{array}$ & Suecia \\
\hline
\end{tabular}




\begin{tabular}{|c|c|c|c|c|c|c|}
\hline & & & & $\begin{array}{l}\text { Military } \\
\text { Modernization }\end{array}$ & & \\
\hline 21 & Matt Ferchen & $\begin{array}{l}\text { The Chinese } \\
\text { Journal of } \\
\text { International } \\
\text { Politics }\end{array}$ & 2011 & $\begin{array}{l}\text { China-Latin America } \\
\text { Relations: Long-term } \\
\text { Boon or Short-term } \\
\text { Boom? }\end{array}$ & $\begin{array}{l}\text { Carnegie } \\
\text { Endowment for } \\
\text { International } \\
\text { Peace }\end{array}$ & $\begin{array}{l}\text { Estados } \\
\text { Unidos }\end{array}$ \\
\hline 22 & $\begin{array}{l}\text { Michael A. } \\
\text { Glosny }\end{array}$ & Polity & 2009 & $\begin{array}{l}\text { China and the BRICs: } \\
\text { A Real (but Limited) } \\
\text { Partnership in a } \\
\text { Unipolar World }\end{array}$ & $\begin{array}{l}\text { Massachusetts } \\
\text { Institute of } \\
\text { Technology }\end{array}$ & $\begin{array}{l}\text { Estados } \\
\text { Unidos }\end{array}$ \\
\hline 23 & $\begin{array}{l}\text { Noesselt, } \\
\text { Nele }\end{array}$ & $\begin{array}{l}\text { Documento } \\
\text { de trabajo }\end{array}$ & 2012 & $\begin{array}{l}\text { Is There a "Chinese } \\
\text { School" of IR?65 }\end{array}$ & $\begin{array}{l}\text { University of } \\
\text { Duisburg-Essen }\end{array}$ & Alemania \\
\hline 24 & Ong, Russell & Routledge & 2007 & $\begin{array}{l}\text { (2007) China's } \\
\text { Security Interests in } \\
\text { the } 21 \text { st Century }\end{array}$ & $\begin{array}{l}\text { SOAS University } \\
\text { of London - } \\
\text { Depratment of } \\
\text { Politics and } \\
\text { International } \\
\text { Studies }\end{array}$ & Inglaterra \\
\hline 25 & $\begin{array}{l}\text { Paltiel, } \\
\text { Jeremy }\end{array}$ & $\begin{array}{l}\text { The Chinese } \\
\text { Journal of } \\
\text { International } \\
\text { Politics }\end{array}$ & 2010 & $\begin{array}{l}\text { Mencius and World } \\
\text { Order Theories }\end{array}$ & $\begin{array}{l}\text { Carleton } \\
\text { University }\end{array}$ & Canadá \\
\hline 26 & Qin, Yaqing & $\begin{array}{l}\text { Documento } \\
\text { de trabajo }\end{array}$ & 2011 & $\begin{array}{l}\text { Qin Yaqing on rules vs } \\
\text { relations, drinking } \\
\text { coffee and tea, and a } \\
\text { chinese approach to } \\
\text { global governance }\end{array}$ & $\begin{array}{l}\text { China Foreign } \\
\text { Affairs } \\
\text { University }\end{array}$ & China \\
\hline 27 & $\begin{array}{l}\text { Resende } \\
\text { Máximo, } \\
\text { Jéssica } \\
\text { Cristina y } \\
\text { Cunha Leite, } \\
\text { Alexandre } \\
\text { César }\end{array}$ & Ponencia $^{67}$ & 2011 & $\begin{array}{l}\text { A debate about culture } \\
\text { as an epistemological } \\
\text { source in the } \\
\text { construction of } \\
\text { International } \\
\text { Relations Theories: the } \\
\text { Chinese academic } \\
\text { production in } \\
\text { International Relations }\end{array}$ & $\begin{array}{l}\text { Pontifica } \\
\text { Universidad } \\
\text { Católica de Río } \\
\text { de Janeiro }\end{array}$ & Brasil \\
\hline 28 & Shi, Yinhong & $\begin{array}{l}\text { Working } \\
\text { paper, } \\
\text { Sasakawa } \\
\text { Peace } \\
\text { Foundation } \\
\text { USA }\end{array}$ & 2002 & $\begin{array}{l}\text { The Rising China: } \\
\text { Essential Disposition, } \\
\text { Secular Grand } \\
\text { Strategy, and Current } \\
\text { Prime Problems }\end{array}$ & $\begin{array}{l}\text { Renmin } \\
\text { University of } \\
\text { China }\end{array}$ & China \\
\hline
\end{tabular}

\footnotetext{
${ }^{65}$ Publicado en el sitio: GIGA Working Paper, No. 188, March 2012

${ }^{66}$ Creutzfeldt, Benjamin (2011): 'Theory Talk \#45: Qin Yaqing on Rules vs Relations, Drinking Coffee and Tea, and a Chinese Approach to Global Governance', Theory Talks, en http://www.theorytalks.org/2011/11/theory-talk-45.html(30-11-2011)

${ }^{67}$ Tercera conferencia de estudios internacional global, Porto 17 al 20 de agoto de 2011
} 


\begin{tabular}{|c|c|c|c|c|c|c|}
\hline 29 & Shi, Yinhong & $\begin{array}{l}\text { Capítulo de } \\
\text { libro }\end{array}$ & 2010 & $\begin{array}{l}\text { The Trajectory and } \\
\text { Implications of } \\
\text { China's Continuing } \\
\text { Rise for Northeast } \\
\text { Asian Regional } \\
\text { Integration }^{68}\end{array}$ & $\begin{array}{l}\text { Renmin } \\
\text { University of } \\
\text { China }\end{array}$ & \\
\hline 30 & Shi, Yinhong & $\begin{array}{l}\text { Working } \\
\text { paper } \\
\text { [Society for } \\
\text { International } \\
\text { Development } \\
\text { ] }\end{array}$ & 2011 & $\begin{array}{l}\text { Universal Norms and } \\
\text { China's Complexity in } \\
\text { Addressing "Global" } \\
\text { Security Challenges }{ }^{69}\end{array}$ & $\begin{array}{l}\text { Renmin } \\
\text { University of } \\
\text { China }\end{array}$ & \\
\hline 31 & $\begin{array}{l}\text { Sugihara, } \\
\text { Kaoru }\end{array}$ & $\begin{array}{l}\text { Oxford } \\
\text { University } \\
\text { Press }\end{array}$ & 2005 & $\begin{array}{l}\text { Japan, China, and the } \\
\text { Growth of the Asian } \\
\text { International } \\
\text { Economy, 1850-1949 }\end{array}$ & Kyoto University & Japón \\
\hline 32 & $\begin{array}{l}\text { Tang, } \\
\text { Shiping }\end{array}$ & $\begin{array}{l}\text { The Chinese } \\
\text { Journal of } \\
\text { International } \\
\text { Politics }\end{array}$ & 2012 & $\begin{array}{l}\text { Outline of a New } \\
\text { Theory of Attribution } \\
\text { in IR: Dimensions of } \\
\text { Uncertainty and Their } \\
\text { Cognitive Challenges }\end{array}$ & Fudan University & China \\
\hline 33 & $\begin{array}{l}\text { Tang, } \\
\text { Shiping }\end{array}$ & $\begin{array}{l}\text { The Chinese } \\
\text { Journal of } \\
\text { International } \\
\text { Politics }\end{array}$ & 2010 & $\begin{array}{l}\text { Offence-defence } \\
\text { Theory: Towards a } \\
\text { Definitive } \\
\text { Understanding }\end{array}$ & Fudan University & China \\
\hline 34 & $\begin{array}{l}\text { Tao, } \\
\text { Wenzhao }\end{array}$ & $\begin{array}{l}\text { Working } \\
\text { Paper }\end{array}$ & 2009 & $\begin{array}{l}\text { Thirty Years of } \\
\text { Research in the } \\
\text { History of Sino-US } \\
\text { Relations in China }{ }^{70}\end{array}$ & $\begin{array}{l}\text { Chinese } \\
\text { Academy of } \\
\text { Social Sciences } \\
\text { Wilson Center }\end{array}$ & $\begin{array}{l}\text { China } \\
\text { Estados } \\
\text { Unidos }\end{array}$ \\
\hline 35 & $\begin{array}{l}\text { Wang, Fei- } \\
\text { Ling }\end{array}$ & $\begin{array}{l}\text { Georgia } \\
\text { Institute of } \\
\text { Technology }\end{array}$ & 1999 & $\begin{array}{l}\text { China's Self-Image } \\
\text { and Strategic } \\
\text { Intentions: National } \\
\text { Confidence and } \\
\text { Political Insecurity }\end{array}$ & Georgia Tech & $\begin{array}{l}\text { Estados } \\
\text { Unidos }\end{array}$ \\
\hline 36 & $\begin{array}{l}\text { Wang, } \\
\text { Gungwu y } \\
\text { Zheng, } \\
\text { Yongnian }\end{array}$ & $\begin{array}{l}\text { World } \\
\text { Scientific } \\
\text { Pub Co Inc }\end{array}$ & 2001 & $\begin{array}{l}\text { (2000) Reform, } \\
\text { Legitimacy and } \\
\text { Dilemmas: China's } \\
\text { Politics and Society }\end{array}$ & $\begin{array}{l}\text { Australian } \\
\text { national } \\
\text { University } \\
\text { National } \\
\text { University of } \\
\text { Singapore }\end{array}$ & $\begin{array}{l}\text { Australia } \\
\text { Singapore }\end{array}$ \\
\hline
\end{tabular}

${ }^{68}$ En Flake, Gordon ed. (2010). Toward an Ideal Security State for Northeast Asia 2025. Washignton DC: The Maureen and Mike Mansfield Foundation

${ }^{69}$ Lecture Series 2010-2011 'Global Values in a Changing World', Society for International Development (SID), 18 April 2011

${ }^{70}$ En línea:

[http://uscet.org/doc/Thirty\%20Years\%20of\%20Research\%20in\%20American\%20Economy\%20and\%20SinoUS\%20Economic\%20Relations\%20in\%20China.pdf] 


\begin{tabular}{|c|c|c|c|c|c|c|}
\hline 37 & $\begin{array}{l}\text { Warmerdam, } \\
\text { Ward }\end{array}$ & $\begin{array}{l}\text { The Chinese } \\
\text { Journal of } \\
\text { International } \\
\text { Politics }\end{array}$ & 2012 & $\begin{array}{l}\text { Is China a Liberal } \\
\text { Internationalist? }\end{array}$ & $\begin{array}{l}\text { Erasmus } \\
\text { University } \\
\text { Rotterdam }\end{array}$ & Holanda \\
\hline 38 & $\begin{array}{l}\text { Yan, } \\
\text { Xuetong } \\
\text { Douglas } \quad \mathrm{H} . \\
\text { Paal }\end{array}$ & Ponencia & 2011 & $\begin{array}{l}\text { China's Rise and } \\
\text { International Order }\end{array}$ & $\begin{array}{l}\text { Renmin } \\
\text { University of } \\
\text { China }\end{array}$ & \\
\hline 39 & $\begin{array}{l}\text { Yan, } \\
\text { Xuetong }\end{array}$ & $\begin{array}{l}\text { China and } \\
\text { World } \\
\text { Affairs }\end{array}$ & 2006 & $\begin{array}{l}\text { The Path for China to } \\
\text { Increase its "Soft } \\
\text { Power" }\end{array}$ & $\begin{array}{l}\text { Tsinghua } \\
\text { University }\end{array}$ & China \\
\hline 40 & $\begin{array}{l}\text { Yan, } \\
\text { Xuetong }\end{array}$ & Libro & 2002 & $\begin{array}{l}\text { Analysis of China's } \\
\text { National Interests }\end{array}$ & $\begin{array}{l}\text { Tsinghua } \\
\text { University }\end{array}$ & \\
\hline 41 & $\begin{array}{l}\text { Yan, } \\
\text { Xuetong }\end{array}$ & $\begin{array}{l}\text { Journal of } \\
\text { Contemporar } \\
\text { y China }\end{array}$ & 2001 & $\begin{array}{l}\text { The Rise of China in } \\
\text { Chinese Eyes }\end{array}$ & $\begin{array}{l}\text { Tsinghua } \\
\text { University }\end{array}$ & China \\
\hline 42 & $\begin{array}{l}\text { Yan, } \\
\text { Xuetong } \\
\text { Qi, Haixia }\end{array}$ & $\begin{array}{l}\text { The } \\
\text { Diplomat }\end{array}$ & 2012 & $\begin{array}{l}\text { How to Avoid a U.S.- } \\
\text { China Cold War }\end{array}$ & $\begin{array}{l}\text { Tsinghua } \\
\text { University }\end{array}$ & China \\
\hline 43 & Yu, Xintian & $\begin{array}{l}\text { Global } \\
\text { Review }\end{array}$ & 2008 & $\begin{array}{l}\text { The Role of Soft } \\
\text { Power in China's } \\
\text { External Strategy }\end{array}$ & $\begin{array}{l}\text { Shanghai } \\
\text { Institutes for } \\
\text { International } \\
\text { Studies }\end{array}$ & China \\
\hline 44 & $\begin{array}{l}\text { Yuan, Jing- } \\
\text { dong }\end{array}$ & $\begin{array}{l}\text { Asian } \\
\text { Perspective }\end{array}$ & 2003 & $\begin{array}{l}\text { The Bush Doctine: } \\
\text { Chinese Perspective } \\
\text { and Responses }\end{array}$ & $\begin{array}{l}\text { The University } \\
\text { of Sydney }\end{array}$ & Australia \\
\hline 45 & $\begin{array}{l}\text { Zachmann, } \\
\text { Matthias }\end{array}$ & Routledge & 2009 & $\begin{array}{l}\text { China and Japan in the } \\
\text { Late Meiji Period: } \\
\text { China policy and the } \\
\text { Japanese discourse on } \\
\text { national identity, } \\
\text { 1895-1904 }\end{array}$ & Frei Universitat & Alemania \\
\hline 46 & $\begin{array}{l}\text { Zhang, Bao- } \\
\text { hui }\end{array}$ & $\begin{array}{l}\text { Journal of } \\
\text { Current } \\
\text { Affairs }\end{array}$ & 2010 & $\begin{array}{l}\text { Chinese Foreign } \\
\text { Policy in Transition: } \\
\text { Trends and } \\
\text { Implications }\end{array}$ & $\begin{array}{l}\text { Lingnan } \\
\text { University }\end{array}$ & $\begin{array}{l}\text { China } \\
\text { (Hong- } \\
\text { Kong) }\end{array}$ \\
\hline 47 & $\begin{array}{l}\text { Zheng, } \\
\text { Yongnian }\end{array}$ & $\begin{array}{l}\text { Cambridge } \\
\text { University } \\
\text { Press }\end{array}$ & 2004 & $\begin{array}{l}\text { Globalization and } \\
\text { State Transformation } \\
\text { in China }\end{array}$ & $\begin{array}{l}\text { National } \\
\text { University of } \\
\text { Singapore }\end{array}$ & Singapore \\
\hline 48 & $\begin{array}{l}\text { Zheng, } \\
\text { Yongnian y } \\
\text { Joseph } \\
\text { Fewsmith }\end{array}$ & Routledge & 2008 & $\begin{array}{l}\text { China's Opening } \\
\text { Society: The Non- } \\
\text { State Sector and } \\
\text { Governance }\end{array}$ & $\begin{array}{l}\text { National } \\
\text { University of } \\
\text { Singapore } \\
\text { Boston } \\
\text { University }\end{array}$ & $\begin{array}{l}\text { Singapore } \\
\text { Estados } \\
\text { Unidos }\end{array}$ \\
\hline
\end{tabular}




\begin{tabular}{|l|l|l|l|l|l|l|}
\hline 49 & Zhu, Zhiqun & $\begin{array}{l}\text { Ashgate } \\
\text { Publishing }\end{array}$ & 2010 & $\begin{array}{l}\text { China's New } \\
\text { Diplomacy Since the } \\
\text { Early 1990s: An } \\
\text { Introduction }\end{array}$ & $\begin{array}{l}\text { Bucknell } \\
\text { University }\end{array}$ & $\begin{array}{l}\text { Estados } \\
\text { Unidos }\end{array}$ \\
\hline 50 & Zhu, Liqun & $\begin{array}{l}\text { Institute for } \\
\text { security } \\
\text { studies }\end{array}$ & 2010 & $\begin{array}{l}\text { China's Foreign Policy } \\
\text { Debates }\end{array}$ & $\begin{array}{l}\text { Institute for } \\
\text { Security Studies } \\
\text { de la European } \\
\text { Union (EUISS) }\end{array}$ & Francia \\
\hline
\end{tabular}

\section{Bibliografía}

Allison, Graham (2017): Destined for War: Can America and China Escape Thucydides's Trap? Boston, Houghton Mifflin Harcourt.

Álvarez, Rodrigo (2017): La estrategia comunicacional de china hacia américa del sur, Santiago, Ediciones Universidad Finis Terrae.

Ba, Alice: "China and ASEAN: Re-navigating Relations for a 21st Century Asia", Asian Survey, vol. 43, n4 (julio-agosto 2003).

Chan, Steve (2008): China, the U.S., and the Power-Transition Theory: A Critique. New York, Routledge.

Glaser, Bonnie y Murphy, Melissa (2009): "Soft power with Chinese characteristics: the ongoing debate", en Chinese Soft Power and its Implications for the United States Competition and Cooperation in the Developing World, Washington DC, Center for Strategic and International Studies.

Glaser, Bonnie y Saunders, Phillip: "Chinese Civilian Foreign Policy Research Institutes: Evolving Roles and Increasing Influence", The China Quarterly, n¹71 (septiembre 2002), pp. 597-616.

Glosny, Michael: "China and the BRICs: A Real (but Limited) Partnership in a Unipolar World", Polity vol. 42 n' 1 (enero 2010).

Li, Xing (2010): The Rise of China and the Capitalist world order. New York, Routledge.

Li, Xing y Fryba Christensen, Stenn (2012): The Rise of China the impact on semi-periphery and periphery countries. Aalborg, Aalborg University Press.

Mearsheimer, John: "The Gathering Storm: China's Challenge to US Power in Asia", The Chinese Journal of International Politics, vol. 3, nº (diciembre 2010).

Mearsheimer, John (2015): The Rise of China and the Decline of the U.S. Army. San Diego, Didactic Press

Muchie, Mammo y Li, Xing (2010): "The Myths and realities of the Rising Powers: Is China a Threat to the Existing World Order?", en The Rise of China and the Capitalist World Order, New York, Routledge.

Opoku-Mensah, Paul (2010): "China and the International Aid System: Transformation or Cooptation?", en The Rise of China and the Capitalist World Order. New York, Ashgate Publishing Limited.

Qin, Yaqing: "Development of International Relations theory in China: progress through debates" International Relations of the Asia-Pacific, vol.11, n² (mayo 2011). 
Ross, César y Montaner, Gonzalo: "La agenda de los estudios de seguridad post 9/11: ¿de qué y quiénes hablan?", Revista de Relaciones Internacionales, Estrategia y Seguridad, vol. 12, n² (julio-diciembre 2017)..

Saalman, Lora: "Between 'China Threat Theory' and 'Chindia': Chinese Responses to India's Military Modernization”, The Chinese Journal of International Politics, vol. 4, ${ }^{\circ} 1$ (marzo 2011).

Shambaugh, David: “China's International Relations Think Tanks: Evolving Structure and Process", The China Quarterly, n'171 (septiembre 2002).

Shi, Yinhong: "The Rising China: Essential Disposition, Secular Grand Strategy, and Current Prime Problems". Asian Voices: Promoting Dialogue Between the US and Asia [working paper], febrero 2002.

Shi, Yinhong: "Universal Norms and China's Complexity in Addressing "Global" Security Challenges", Lecture Series 2010-2011 'Global Values in a Changing World', 18 de abril de 2011

Sun-Tzu.(2007): El Arte de la Guerra. Buenos Aires, Longseller.

Tucídides (1986): La Guerra del Peloponeso. Madrid, Ediciones Orbis S.A.

Veg, Sebastian (2019): Minjian: The Rise of China's Grassroots Intellectuals. New York, Columbia University Press.

Woodhead, Arthur Geoffrey (1970): Thucydides on the Nature of Power. New York, Harvard University Press

Xuetong, Yang: "China's Rise and International Order [lecture]". Carnegie Endowment for International Peace, 7 de noviembre de 2011.

Xuetong, Yang: "The Path for China to Increase its "Soft Power", China and World Affairs, vol. 2, n'1 (abril 2006).

Xuetong, Yang: "The Rise of China in Chinese Eyes", Journal of Contemporary China, vol. $10, \mathrm{n}^{\circ} 26$ (agosto 2001).

Xuetong, Yang y Haixia, Qi: "How to Avoid a U.S.-China Cold War, The Diplomat, 25 de septiembre de 2012.

Xufeng, Zhu y Xue, Lan: “Think Tanks in Transitional China”, Public Administration and Development, $\mathrm{n}^{\circ} 27$, (noviembre 2007).

Xufeng, Zhu: "The Influence of Think Tanks in the Chinese Policy Process: Different Ways and Mechanisms", Asian Survey, vol. 49, n² (marzo-abril 2009).

Yu, Xintian: "The Role of Soft Power in China's External Strategy”, Guoji Wenti Yanjiu, 13 de marzo 2008.

Yuan, J. The Bush Doctine: Chinese Perspective and Responses. Asian Perspective , 27 (4) (Enero 2003), pp.111-145.

Zhang, Baohui: "Chinese Foreign Policy in Transition: Trends and Implications", Journal of Current Chinese Affairs, vol.39, n², (junio 2010).

Zhu, Liqun (2010): China's Foreign Policy Debates. Paris, Institute for Security Studies.

\section{Patentes:}

Ross, C. (2016). Patent No. 268.546. Chile. 